See discussions, stats, and author profiles for this publication at: https://www.researchgate.net/publication/334535910

On the systematic status of the genus Oriocalotes Günther, 1864 (Squamata: Agamidae: Draconinae) with the description of a new species from Mizoram state, Northeast India

Article in Zootaxa July 2019

DOI: 10.11646/zootaxa.4638.4.1

CITATIONS

0

9 authors, including:

Varad Giri

88 PUBLICATIONS 990 CITATIONS

SEE PROFILE

Stephen Mahony

University College Dublin and Natural History Museum, London

51 PUBLICATIONS 538 CITATIONS

SEE PROFILE
READS

561

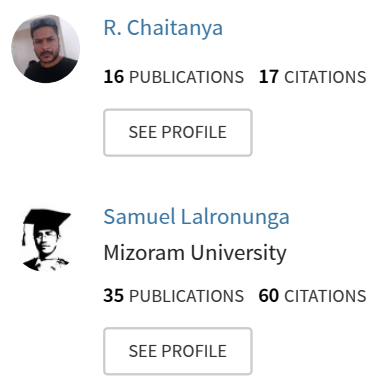

Some of the authors of this publication are also working on these related projects:

Venom gland transcriptomics, venom proteomics and DNA bar coding of major venomous snakes in Indian sub-continent View project

Phylogeny and biogeography of Hemidactylus geckos of Indian subcontinent. View project 


\title{
On the systematic status of the genus Oriocalotes Günther, 1864 (Squamata: Agamidae: Draconinae) with the description of a new species from Mizoram state, Northeast India
}

\author{
VARAD. B. GIRI ${ }^{1}$, R. CHAITANYA ${ }^{2}$, STEPHEN MAHONY ${ }^{3,4,10}$, SAMUEL LALROUNGA ${ }^{5}$, \\ C. LALRINCHHANA ${ }^{6}$, ABHIJIT DAS $^{7}$, VIVEK SARKAR ${ }^{8}$, PRAVEEN KARANTH $^{9} \&$ V. DEEPAK ${ }^{3,9,10}$ \\ ${ }^{1}$ National Centre for Biological Sciences, TIFR, Bangalore, 560065, India \\ 2508, 8 B Cross, Asha Township, Doddagubbi village, Bangalore, 560077, India. \\ ${ }^{3}$ Department of Life Sciences, The Natural History Museum, London SW7 5BD, UK \\ ${ }^{4}$ School of Biology and Environmental Science, University College Dublin, Belfield, Dublin 4, Ireland. \\ ${ }^{5}$ Department of Environmental Science, Pachhunga University College, Aizawl, 796001, India. \\ ${ }^{6}$ Holy Child School, Nalkata, Tripura 799263 India. \\ ${ }^{7}$ Wildlife Institute of India, Chandrabani, P.O. 18, Dehradun, India. \\ ${ }^{8}$ UNESCO Category-2 Center, Wildlife Institute of India, Chandrabani, P.O. 18, Dehradun, India. \\ ${ }^{9}$ Centre for Ecological Sciences, Indian Institute of Science, Bangalore, 560012, India. \\ ${ }^{10}$ Corresponding authors.E-mail:veerappandeepak@gmail.com, stephenmahony2@gmail.com
}

\begin{abstract}
The montane agamid lizard genus Oriocalotes is currently considered monotypic, represented by the species, O. paulus. The systematic status of this taxon has remained questionable since its initial descriptions in the mid-1800s. A detailed molecular and morphological study was carried out to assess the validity of this genus, and its systematic position within the Asian agamid subfamily, Draconinae. Freshly collected and historical museum specimens from the type locality of $O$. paulus were examined morphologically, along with additional samples collected from localities in Mizoram state, Northeast India. Utilising newly generated molecular sequences (two mitochondrial and three nuclear genes), combined with those previously published for representative genera from the subfamilies Draconinae and Agaminae, Maximum Likelihood and Bayesian phylogenetic trees were constructed. Phylogenetic results suggest that Oriocalotes is part of the widespread South and Southeast Asian radiation of Calotes. Comparative morphological studies (including external morphology, hemipenis and osteology) between Oriocalotes and related genera further support this systematic placement. Oriocalotes is herein regarded as a junior subjective synonym of Calotes. Calotes paulus comb. nov. is also assigned a lectotype and given a detailed redescription based on the lectotype, paralectotypes and additional topotypic material. Furthermore, the specimens collected from Mizoram populations are found to be morphologically and genetically distinct from Calotes paulus comb. nov., and are described herein as a new species, Calotes zolaiking sp. nov.
\end{abstract}

Key words: Agamids, biodiversity, Calotes, Khasi Hills, Meghalaya, taxonomy

\section{Introduction}

A new agamid lizard, Agama minor Hardwicke and Gray, 1827, was described based on an unpublished color sketch in the collection of Thomas Hardwicke (Hardwicke NHMUK archives No. 82) of a specimen from Chittagong [now in Bangladesh]. Subsequently, Calotes minor Gray, 1845 was described based on three specimens from "Affghanistan" and one from "Khassia hill" (currently in Meghalaya state, Northeast India), under which Gray (1845) included, and thus inadvertently synonymised, Agama minor Hardwicke and Gray (Smith 1935; Deepak et al. 2015). Günther (1864) created the monotypic genus Oriocalotes Günther, 1864 for the species Calotes minor Gray. Günther (1864) used the following suite of characters to diagnose his new genus "Tympanum naked, back and sides covered with scales of moderate size, between which larger ones are intermixed; their tips are directed backwards and upwards; a spine behind the supraciliary edge. Dorsal crest present, formed by non-united spines, less distinct in the female than in the male. Gular sac none. Tail rounded, with keeled scales below, which are as broad as long." 
He also provided a brief redescription of the species based on the type series of Calotes minor Gray (but not Agama minor Hardwicke and Gray), and included an additional specimen collected by "Messrs. v. Schlagintweit" from Sikkim (Günther 1864).

Subsequently, three additional species were added to the genus: Oreocalotes[sic] major Jerdon, 1870 described from the western Himalayas, $O$. discolor Anderson, 1870 which appeared in a specimen checklist from Burma, and O. kakhienensis Anderson, 1879 also described from Burma. Theobald (1876) transferred both Oriocalotes minor (Gray) and O. major Jerdon to the now synonymised (under Psammophilus Fitzinger, 1843) genus, Charasia Gray, 1845. Theobald's reclassification was broadly based on characters of the dorsal and lateral part of the body, having small keeled scales interspersed with some larger ones. Boulenger (1885), considered Oriocalotes and Charasia to be synonyms of Acanthosaura Gray, 1831, transferring three of the species, O. minor, O. major and O. kakhienensis by implication. He used characters such as the continuity of the nuchal and dorsal crests and the presence of a spine on each side of the neck to diagnose Acanthosaura minor (Gray). Smith (1935), for the first time, addressed the taxonomic heterogeneity of Calotes minor Gray where he elevated Agama minor Hardwicke and Gray from the synonymy of Calotes minor Gray based on its short tail, regular scalation and coloration of the body of the former, as opposed to heterogenous, regularly arranged dorsal scales, and a post orbital spine in the latter species. Smith (1935) also resurrected the genus Oriocalotes Günther for Calotes minor Gray, citing the validity of its original description. Despite both species being in separate genera, Smith mistakenly assumed that there was an issue of homonymy created by the elevation of Agama minor Hardwicke and Gray from Calotes minor Gray, and created the replacement species epithet "paulus" for Calotes minor Gray, in the new combination Oriocalotes paulus Smith, 1935. Smith's replacement name "paulus" was therefore unjustified and so Oriocalotes minor (Gray) should be the valid name, however Smith's action has remained unquestioned until now and Oriocalotes paulus is the only name in use for this taxon (e.g., Wermuth 1967; Moody 1980; Diong \& Lim 1998; Manthey \& Schuster 1999; Manthey \& Denzer 2000; Zhao et al. 2000; Mahony 2010; Venugopal 2010; Ananjeva et al 2011; Huang et al. 2011; Deepak et al. 2015). Smith (1935) assigned Jerdon's O. major to the genus Japalura Gray, 1853 (where it remains today), and O. kakhienensis to the genus Calotes Cuvier, 1817. The forgotten name, Oriocalotes discolor, was recently demonstrated to represent a nomen oblitum and a senior objective synonym of $O$. kakhienensis, which is currently assigned to the genus Pseudocalotes Fitzinger, 1843 (Mahony 2010), rendering Oriocalotes monotypic. Agama minor Hardwicke and Gray is now placed in the genus Calotes as C. minor (Hardwicke \& Gray) (Deepak et al. 2015). Although the validity of the genus Oriocalotes has not been questioned until now (e.g., Wermuth 1967; Moody, 1980; Manthey \& Schuster 1999; Ananjeva et al. 2011), its systematic relationship within Draconinae Fitzinger, 1826 has remained uncertain (Mahony 2010).

In this study, we resolve the systematic position of the genus Oriocalotes within Draconinae, based on an integrated taxonomic approach utilising morphological and molecular data. We provide a detailed description of the herein assigned lectotype of $O$. paulus and include morphological variation for the species. We also determine the taxonomic status of recently discovered populations of Oriocalotes from Mizoram that are morphologically and genetically distinct from the type species.

\section{Materials and methods}

Specimen collection and preservation: Fieldwork was carried out at Sohra, Meghalaya state, Northeast India from October, 2014 to December, 2018 by Vivek Sarkar, and in Mizoram state, Northeast India from September, 2010 to April, 2018 by C. Lalrinchhana and Samuel Lalronunga. Specimens were located during opportunistic visual searches of sub-tropical forest and surrounding open habitats. Live individuals were collected by hand and photographed in life for documentation of coloration. Tissue samples were extracted after specimen euthanisation, before fixation, and were stored at $-20^{\circ} \mathrm{C}$ in absolute ethanol. Specimens were first fixed in $4 \%$ formalin in the field, and later transferred to $70 \% \mathrm{EtOH}$ for long-term storage.

Abbreviations. Museum acronyms are as follows: NCBS (National Centre for Biological Sciences, Bengaluru, India), BNHS (Bombay Natural History Society Museum, Mumbai, India), NHMUK (Natural History Museum, London, UK: specimens are referred to under the original acronym BMNH, British Museum [Natural History], for comparability with historical literature), ESV and CESG (Centre for Ecological Sciences, Indian Institute of Science, Bengaluru, India). Meters above sea level (m a.s.1.). 
Gene sequences. Sampling for this study was carried out in Meghalaya and Mizoram states in Northeast India (Fig. 1). A tissue sample from a Meghalaya (NCBS AQ198) and Mizoram (NCBS AU155) specimen of Oriocalotes were used in this study. Additional sequences were generated for one sample of Calotes calotes (Linnaeus, 1758) (CESG 554), Calotes emma Gray, 1845 and Calotes mystaceus Duméril \& Bibron, 1837, Psammophilus cf. blanfordanus (Stoliczka, 1871) (CESG 461), Salea anamallayana (Beddome, 1878), Sarada deccanensis (Jerdon, 1870), Sitana ponticeriana Cuvier, 1829 and Sitana spinaecephalus Deepak, Vyas and Giri, 2016 (Table 1). Genomic DNA was extracted from liver and tail tip tissue samples that were stored frozen at $-20^{\circ} \mathrm{C}$ in absolute ethanol. DNeasy ${ }^{\circledR}$ Blood \& Tissue Kit (Qiagen ${ }^{\circledR}$, Germany) following manufacturer's instructions. Partial sequences of the mitochondrial genes, nicotinamide adenine dinucleotide dehydrogenase subunit 2 (ND2: 1059 bp [base pairs]) and partial 16S rDNA (16S: $486 \mathrm{bp}$ ), and partial sequences from the nuclear genes, recombination activating gene 1 (RAG1: 1000 bp), prostaglandin E2 receptor gene (PTGER: 470 bp), and G protein-coupled receptor R35 (R35: 665 bp), were PCR amplified and sequenced using published primers (Palumbi et al. 1991; Macey et al. 1997; Macey et al. 2000; Groth \& Barrowclough 1999; Leaché 2009, respectively). PCR amplifications were carried out in $25 \mu 1$ aliquots containing $2.5 \mu \mathrm{L}$ of 1 X Taq buffer, $2.5 \mu \mathrm{L}$ of $2.5 \mathrm{mM}$ dNTP, $2.5 \mu \mathrm{L}$ of $2.5 \mathrm{mM}$ of $\mathrm{MgCl}_{2}, 0.25 \mu \mathrm{l}$ each for the forward and reverse primer, $0.33 \mu 1$ of 2 units of Taq DNA polymerase, $1 \mu 1$ of extracted DNA of the sample and $16.67 \mu \mathrm{l}$ of PCR grade $\mathrm{H}_{2} \mathrm{O}$. We used a $\mathrm{S} 1000^{\mathrm{TM}}$ Thermal Cycler (Bio-Rad, USA) to run the PCR. The PCR conditions were as follows: initial denaturation at $94^{\circ} \mathrm{C}$ for $3 \mathrm{~min}$, denaturation for 35 cycles at $94^{\circ} \mathrm{C}$ for $50 \mathrm{~s}$, annealing (at $45^{\circ} \mathrm{C}$ for $16 \mathrm{~S}, 53^{\circ} \mathrm{C}$ for ND2 \& RAG1, between $53^{\circ} \mathrm{C}$ and $58^{\circ} \mathrm{C}$ temperature range for PTGER \& R35) for $1 \mathrm{~min}$, and extension at $72{ }^{\circ} \mathrm{C}$ for $40 \mathrm{~s}$. The final extension was at $4^{\circ} \mathrm{C}$ for $30 \mathrm{~min}$. Amplified PCR products were ran on $2 \%$ agarose gel, viewed in an Essential V4 (UVITEC Cambridge, UK) gel documentation system, and purified using a QIAquick PCR Purification Kit (Qiagen ${ }^{\circledR}$, Germany). PCR products were Sanger sequenced for the forward and reverse strand at Medauxin Sequencing Services (Bangalore, India). Sequence chromatograms were checked and edited using the program Chromas LITE ver.2.1.1. Sequences were subjected to NCBI nucleotide BLAST search to verify approximate identities.
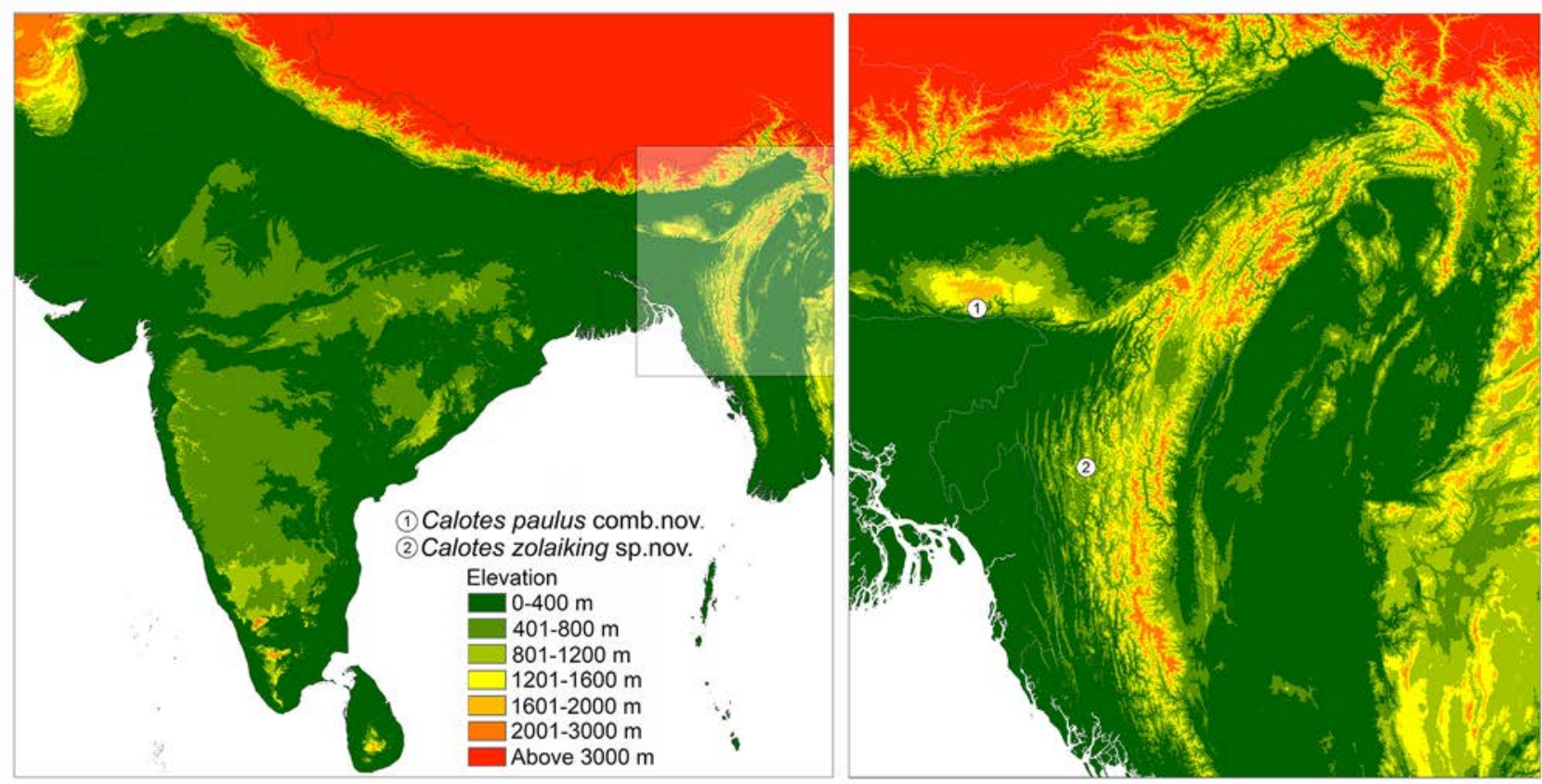

FIGURE 1. Map showing type locality of Calotes paulus comb. nov. and Calotes zolaiking sp. nov. in North East India.

Phylogenetic analyses. In addition to the sequences generated in this study, sequences for 47 other agamids were downloaded from GenBank (Benson et al. 2017), selecting species and vouchers with the maximum gene coverage to correspond with our molecular dataset (Table 1). Species from the sister subfamily Agaminae (Table 1) were selected as outgroup taxa for Draconinae, based on the molecular phylogenetic results of Pyron et al. (2013). The per-gene coverage for the 50 sequences used in this study were as follows: ND2 86\%, 16S 50\%, R35 28\%, PTGER 26\% and RAG1 20\%. Sequences were aligned using ClustalW in MEGA 5.1 (Higgins et al. 1994; Tamura et al. 2011). All gene sequences except $16 \mathrm{~S}$ were adjusted for open reading frames and checked for stop codons. Align- 


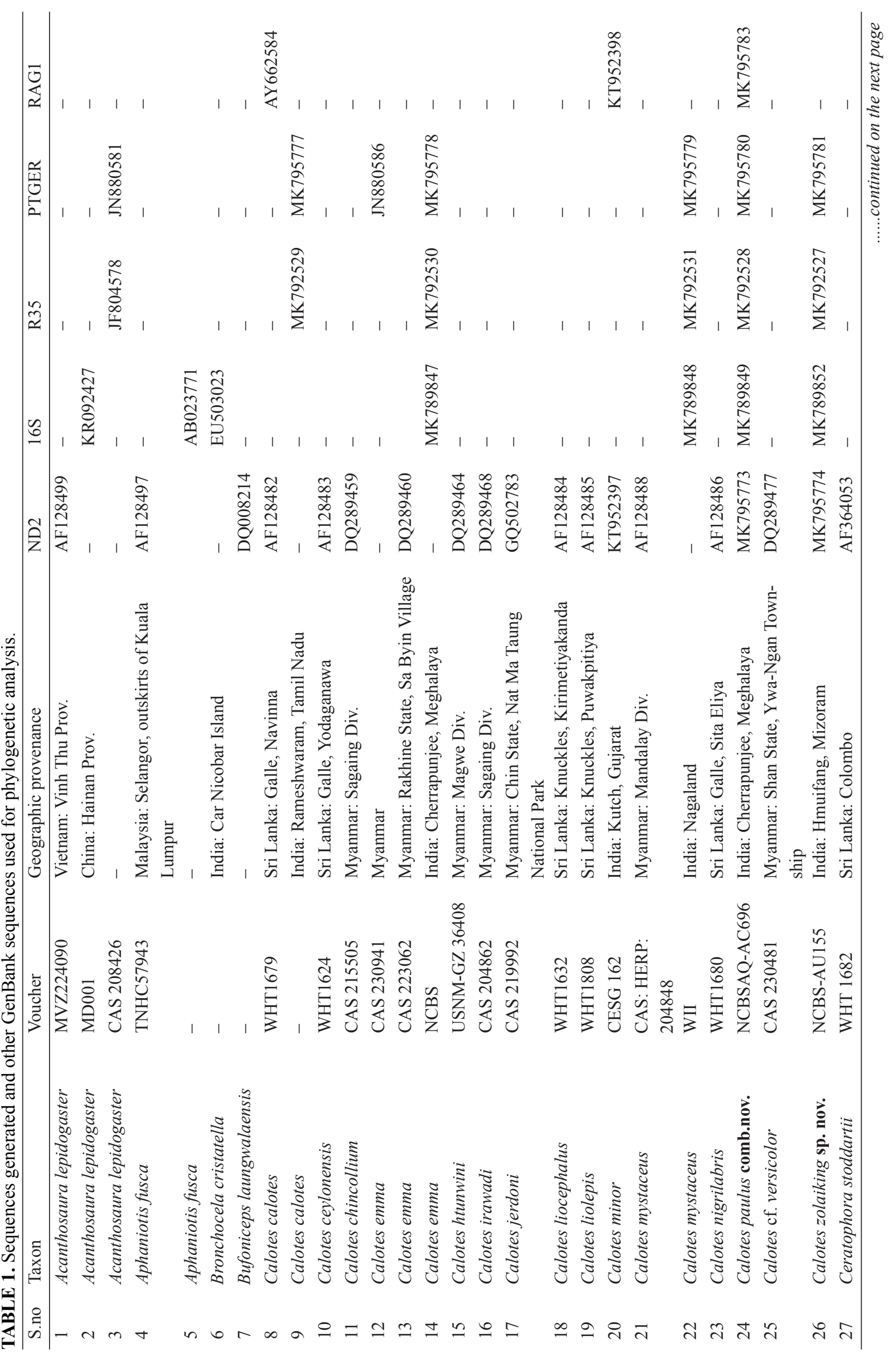




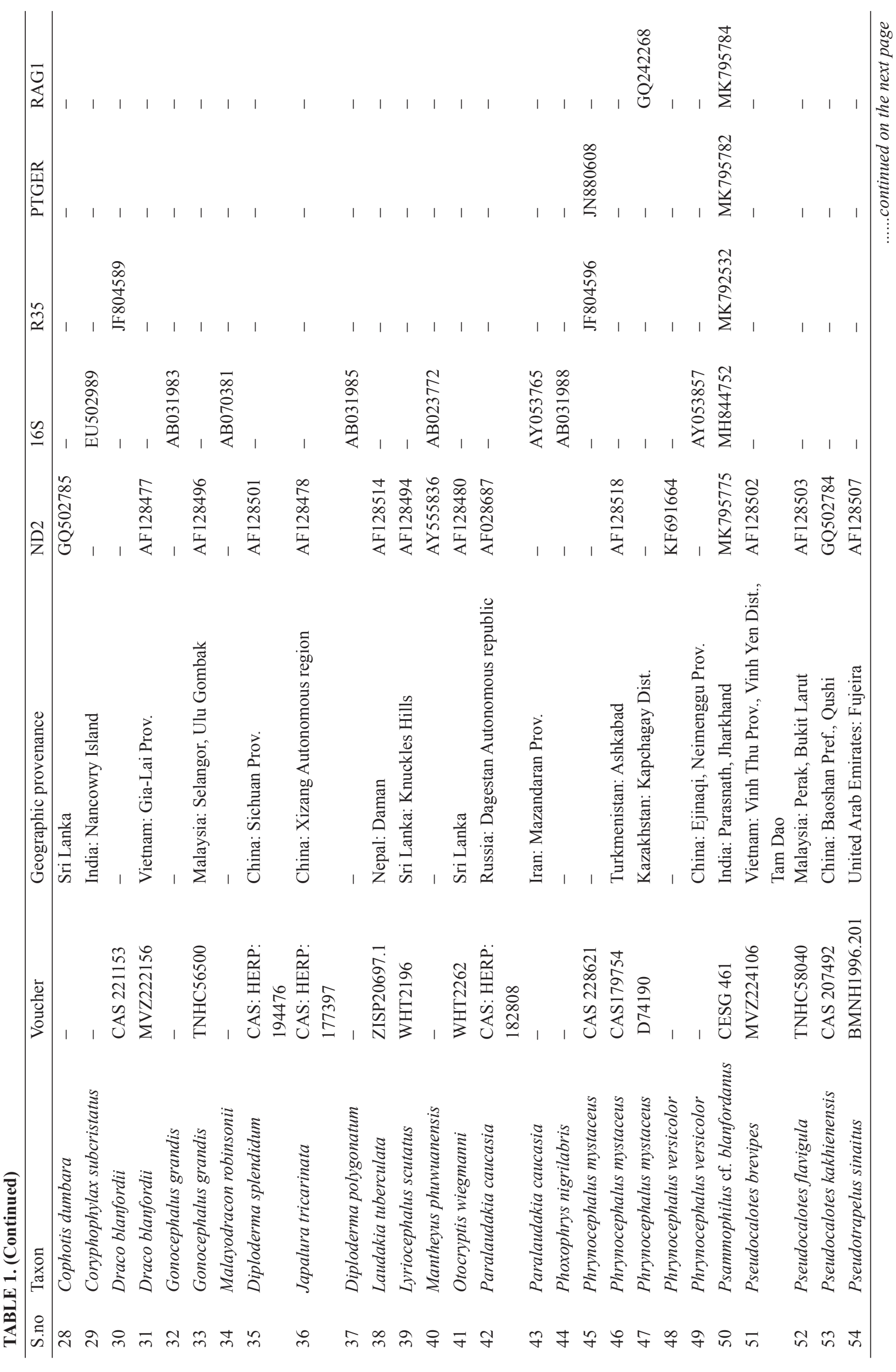




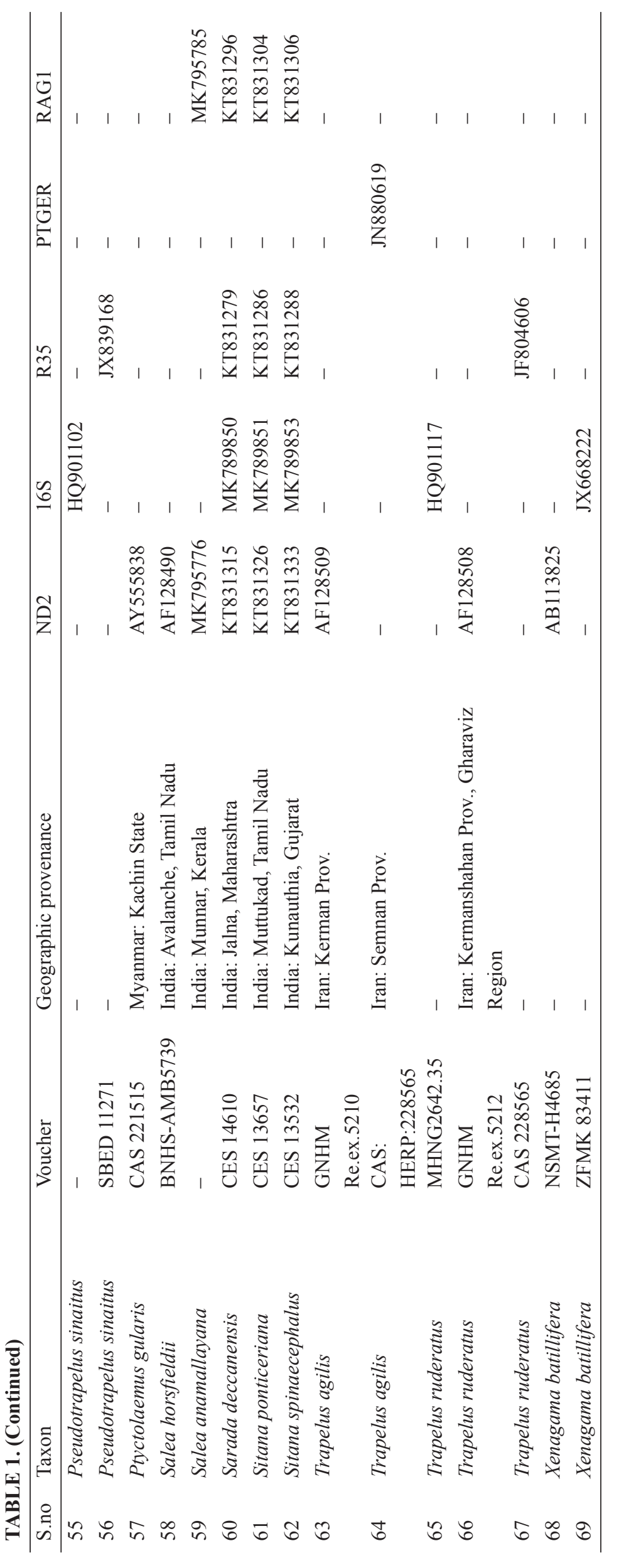


ments were checked and adjusted by eye for the ND2 gene beyond $955 \mathrm{bp}$ and the multiple hypervariable regions in the 16S gene. Uncorrected genetic $p$-distances between taxa were calculated for the ND2 sequences using MEGA 5.1 (Tamura et al. 2011). PartitionFinder v1.1.1 (Lanfear et al. 2012) was used to find the best partition scheme and model of sequence evolution for each partition. The coding genes were defined before subjecting to PartitionFinder analysis and the optimal partitioning scheme included four partitions for the mitochondrial DNA (mtDNA) dataset and four partitions for the nuclear DNA (nDNA) dataset (Appendix I).

Concatenated mtDNA and concatenated nDNA alignments were analysed separately using a Maximum Likelihood (ML) and a Bayesian (BI) approach. ML trees were generated using the GUI version of RAxML (Silvestro \& Michalak 2012; Stamatakis et al. 2005) with 1000 bootstrap replicates in ML + rapid bootstrap settings. ML analysis in RaxML permits only one model of sequence evolution in the analysis, therefore we used GTR $+\mathrm{G}$ for all five partitions. We used GTR + G model in RAxML which is recommended over the GTR $+\mathrm{G}+\mathrm{I}$ because the 25 rate categories account for potentially invariant sites (Stamatakis 2006). Individual ML nuclear gene trees were also generated to determine gene concordance and degree of phylogenetic signal. Bayesian trees were generated using the program MrBayes 3.2 (Ronquist et al. 2012) under default prior settings and with all eight partitions assigned their optimum model as determined by PartitionFinder (Appendix. 1). For BI analyses, two separate runs using 4 Markov chains each were initiated from random trees and allowed to run for 1 million generations sampling every 100 generations. Analyses were terminated when the standard deviation of split frequencies were less than 0.005 , the first $25 \%$ of trees were discarded as "burn-in", and trees were constructed under $50 \%$ majority consensus rule.

External morphology. Measurements (to the nearest $0.1 \mathrm{~mm}$ ) were taken with digital calipers (Mitutoyo ${ }^{\mathrm{TM}}$, Japan), except tail length (TL) which was measured using a string and a ruler. Morphometric characters were measured as follows: snout to vent length (SVL, from tip of snout to anterior border of cloaca), Trunk length (TrL, axilla to groin length), tail length (TL, from posterior border of cloacal opening to tip of tail), tail depth (TaD) and tail width (TW) taken at the highest and widest points respectively, head length (HL, from snout tip to jaw angle), head width (HW, measured at posterior axis of jaw), head depth (HD, dorsoventral distance from top of head to underside of jaw at transverse plane intersecting posterior axis of jaw), snout-eye length (SE, from snout tip to anterior border of orbit), naris to eye (NE, from anterior edge of orbit to posterior edge of naris), eye to ear (EE, from posterior border of orbit to anterior border of tympanum), inter-orbital width (IO, transverse distance between anterodorsal most borders of left and right orbits), tympanum diameter (TD, greatest diameter of tympanum), orbit diameter (OD, greatest diameter of orbit), snout to forelimb insertion (SFI, between tip of snout to anterior insertion of forelimb), upper arm length (UAL, from anterior insertion of forelimb to elbow), lower arm length (LAL, from elbow to distal end of wrist), hand length (HaL, from proximal end of wrist to distal most point of fourth finger, excluding claw), fourth finger length (4FL, distance from juncture of fourth and third finger to distal most point of fourth finger, excluding claw), upper leg length (ULL, length of thigh from groin to knee), lower leg length (LLL, length of crus [tibia] from knee to heel), foot length (FOL, from proximal end of heel to tip of fourth toe, excluding claw), fourth toe length (4TL, distance from juncture of fourth and third toe to distal most point of fourth toe, excluding claw).

The following meristic characters were scored: mid-body scale rows (MSR, number of scale rows around trunk at midbody), scales between superciliaries ( $\mathrm{SnS}$, transverse scale count between anterior superciliaries), scales between orbital spines (HeadSTr, transverse scale count between orbital spines), canthal scales (CS, scale row between posterior margin of nasal scale and anterior margin of orbit), supralabials (SL, posterior end defined by last enlarged scale that contacts an infralabial at posterior axis of jaw), infralabials (IL, posterior end defined by posterior-most enlarged scale that contacts a supralabial at posterior axis of jaw), vertebral scales (VS, scales counted from first nuchal spine to level directly above cloacal opening), fourth finger lamellae (4FLam, number of fourth finger lamellae, from $1^{\text {st }}$ transversely enlarged lamella at base of digit to distal most lamella), fourth toe lamellae (4TLam, number of fourth toe lamellae, from $1^{\text {st }}$ lamella at base of digit to distal most lamella), nuchal crest (NC, number of spines that make up the nuchal crest).

Hemipenes morphology and osteology. Hemipenes were everted using $4 \%$ formalin during the preservation of two euthanised Mizoram Oriocalotes specimens (NCBS-AU156 \& NCBS-AU155). Drawings were made using a Leica $^{\mathrm{TM}}$ M165C (Leica, Germany) microscope mounted camera lucida. Morphological terminology follows Dowling and Savage (1960). Hemipenial characters of the Mizoram Oriocalotes specimen were compared with other draconine lizards (Maduwage et al. 2008). After morphological data had been assessed, one adult male (SVL = $62.9 \mathrm{~mm}$ ) of the Mizoram Oriocalotes specimen (NCBS-AU156) was cleared and stained following the protocol of Hanken and Wassersug (1981). Skull was hand prepared, diluted Sodium hypochlorite was used in to remove tissues attached to the bone. Data on skeletal characters followed standard terminology (Moody 1980; Romer 1956; 
Oelrich 1956). Diagnostic osteological characters specified by Moody (1980) for Calotes and Pseudocalotes were compared with Oriocalotes for further evidence of systematic association.

\section{Results and discussion}

Systematics. The overall ML tree topology of Draconinae obtained using the mtDNA dataset (Fig. 2) was similar to previous studies (see Schulte et al. 2004; Pyron et al. 2013; Grismer et al. 2016) in having Mantheyus phuwuanensis (Manthey and Nabhitabhata, 1991) as the sister taxon to all other draconine genera. However, this relationship conflicted with the BI tree of the mtDNA dataset which had a poor node support (Fig. 3). Grismer et al. (2016), using next generation sequencing data, identified three problematic relationships within Draconinae, one of which was the placement of Salea Gray, 1845 as the sister taxon of Calotes. Despite adding more genera and different gene sequences in our study, Salea was not sister to Calotes in concatenated mtDNA trees. Since Psammophilus was not included in Grismer et al. (2016) we did not constrain the monophyly of Salea + Calotes. There are still many gaps in molecular phylogenetic sampling of Draconinae, which is probably one of the reasons why relationships between genera and species remains unresolved. Psammophilus was resolved (with high support) as sister to a clade comprising Calotes + Oriocalotes in both the mitochondrial and nuclear phylogenies, and this arrangement received high support (Figs. 2, 3, \& 4). Both ML and BI trees from the concatenated mitochondrial dataset (ND2 + 16S) demonstrated that Calotes is paraphyletic with respect to Oriocalotes (Figs. $2 \& 3$ ). Within the larger Calotes clade, Oriocalotes was resolved as sister to a subclade comprised of species from Northeast India and Southeast Asia: $C$. emma, C. chincollium Vindum, 2003 and C. mystaceus. The ML and BI trees for the concatenated nuclear dataset (R35 + PTGER + RAG1) both placed Oriocalotes within the Calotes radiation but showed conflicting relationships within this radiation. The ML tree placed Oriocalotes as sister to Calotes calotes, but with weak support (Fig. 4a), whereas in the BI tree Oriocalotes samples formed a polytomy with Calotes calotes (Fig. 4b). The Oriocalotes samples from Mizoram was also consistently resolved as a sister taxon to Oriocalotes paulus on all trees, with high support. Since both nuclear and mitochondrial trees supported placing Oriocalotes within the Calotes radiation, we herein formally synonymise Oriocalotes Günther, 1864, with Calotes Cuvier, 1817.

The uncorrected genetic $p$-distance for the ND2 sequences between the Mizoram Calotes species and Calotes paulus comb. nov. from Meghalaya was 13\% (Appendix 3). This genetic distance is comparable with, or considerably exceeds that observed between other currently recognised Calotes species that were resolved as sister taxa on the mtDNA trees (Figs. $2 \&$ 3), e.g., between C. nigrilabris Peters, 1860 and C. liolepis Boulenger, $1885(p=13 \%)$, between C. versicolor (Daudin, 1802) and C. irawadi Zug, Brown, Schulte and Vindum, 2006 ( $p=6 \%$ ), and only marginally lower than the distance between other closely related species, e.g., between $C$. versicolor/C. htunwini Zug and Vindum, 2006 and C. calotes ( $p=15 \%$ : Appendix 3). The comparatively high $p$-distance observed between the Mizoram populations of Calotes sp. and Calotes paulus comb. nov. in combination with morphological differences (see comparisons sections) are herein considered sufficient to recognise these genetic haplotypes as distinct species.

\section{Taxonomy}

The synonymy of Oriocalotes into Calotes creates some nomenclatural issues that require explanation. Technically Oriocalotes paulus is an unnecessary substitute name for Calotes minor Gray, and regardless of its prevailing usage in scientific literature, it is a nomenclaturally invalid name. However, Article 10.6 of the International Code of Zoological Nomenclature (ICZN, 1999) states that invalidity does not affect availability of such names, and Smith's replacement name qualifies as an available (but invalid) junior objective synonym of Calotes minor Gray by meeting the requirements of Articles 11 and 13.1. Our proposed synonymy of Oriocalotes makes Calotes minor Gray an invalid (but available) junior secondary homonym of the older Calotes minor (Hardwicke \& Gray) that needs to be replaced following Article 60.1: "Substitute names. A junior homonym [Art. 53] must be rejected and replaced either by an available and potentially valid synonym [Art. 23.3.5] or, for lack of such a name, by a new substitute name [Art. 60.3].". Following the Principle of Priority, Article 23.3.5 states that "The Principle of Priority requires that if a name in use for a taxon is found to be unavailable or invalid it must be replaced by the next oldest available 
name from among its synonyms, providing that that name is not itself invalid. If the rejected name has no potentially valid synonym a new substitute name (see Article 60.3) must be established in its place". This means that despite the nomenclatural availability of Oriocalotes paulus, its invalidity prevents the application of it as a substitute/replacement name. Further, Article 60.3 states "Junior homonyms without synonyms. If the rejected junior homonym has no known available and potentially valid synonym it must be replaced by a new substitute name, with its own author and date; this name will then compete for priority with any synonym recognised later". The purpose of the ICZN is to maintain nomenclatural stability, and favours the avoidance of creating new names that may lead to confusion. Rather than creating a new substitute name, an application will be made to the ICZN to treat the species epithet "paulus Smith" as a valid substitute name and nomen protectum for Calotes minor Gray. Pending a ruling from the ICZN we will continue to use Smith's species name in the new combination Calotes paulus (Smith, 1935) comb. nov.

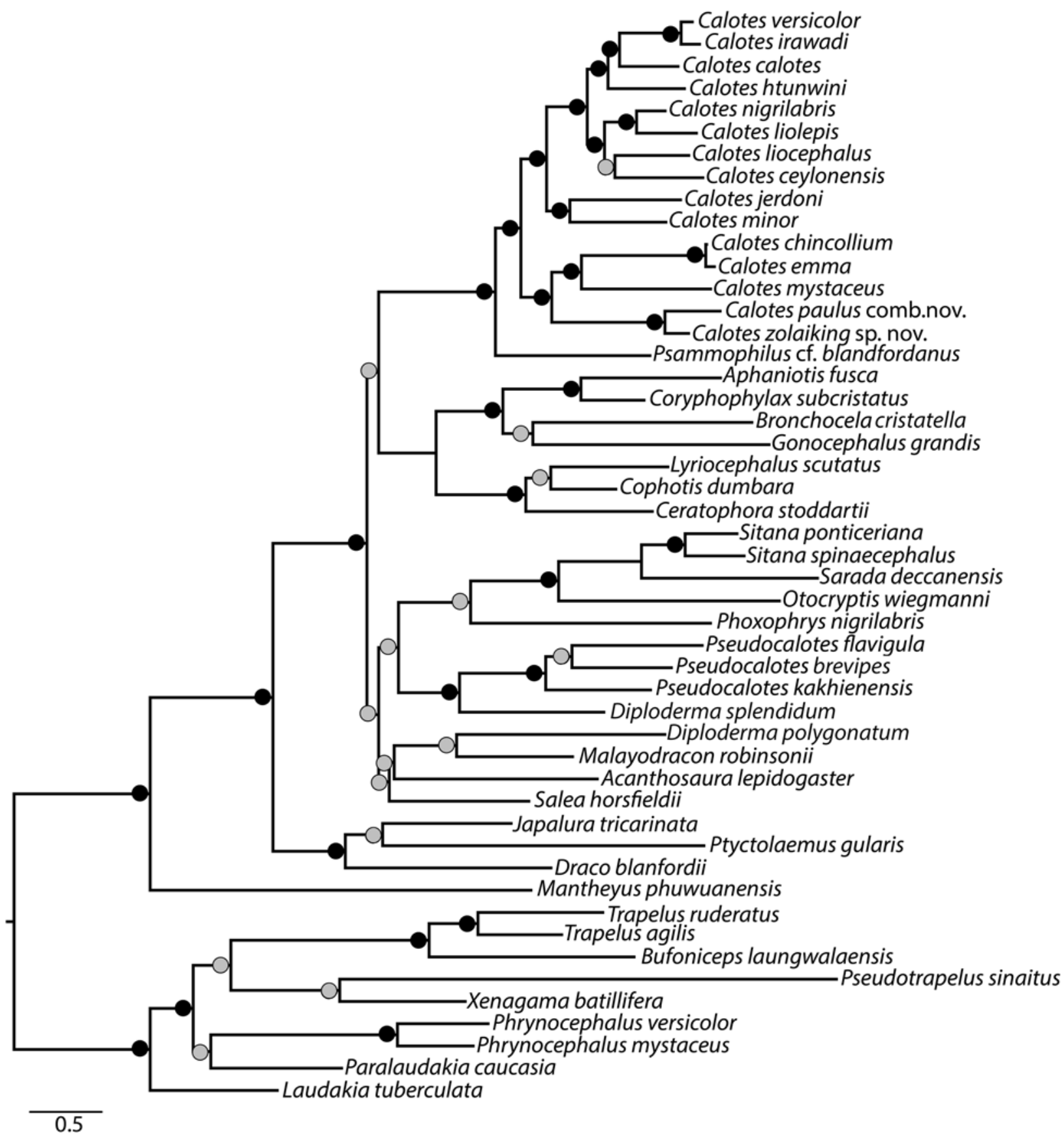

FIGURE 2. ML phylogeny built using the concatenated ND2 + 16S mitochondrial dataset. Bootstrap support $>90$ dark circle; $<90$ grey circle. 


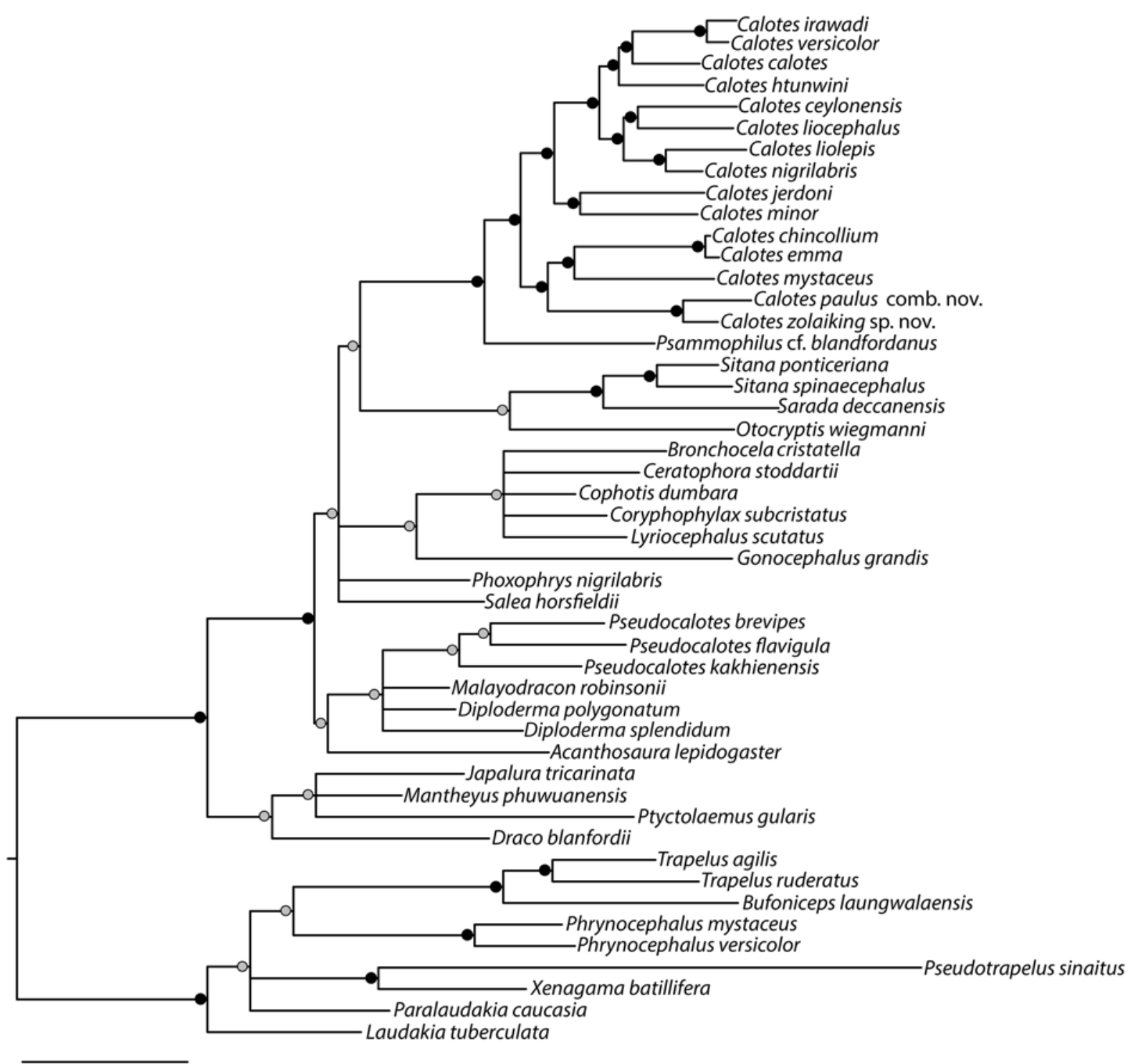

FIGURE 3. BI phylogeny of the mitochondrial (ND2 + 16S) dataset. Posterior probability $>90$ dark circle; $<90$ grey circle.

The syntype series of Calotes paulus comb. nov. is comprised of specimens presented from the East India Company from "Affghanistan" and "Khasia hill", of which the former locality is considered in error. Though we concur with Günther (1864) that the "Affghanistan" specimens were likely to have originated from the Khasi Hills, and our morphological examination of specimens suggests that the syntype series are conspecific, the origin of these specimens is not confirmed at this time (refer to the "Distribution and natural history" section below for further discussion). Considering the discovery presented here of a second, morphologically very similar sister species, we herein designate a lectotype for Calotes paulus comb. nov. for the purpose of restricting the name bearing type to a single specimen.

\section{Calotes paulus (Smith, 1935) comb. nov.}

Figs. 5 and 6; Table 2 and 5.

Calotes minor Gray, 1845:244 (partim: "Affghanistan” \& "Khassia hill”).

—Oriocalotes minor Günther 1864:147 (partim: “Afghanistan”, "Khasya” \& “Sikkim”).

-Oreocalotes [sic] minor Jerdon 1870:77.

-Charasia minor Theobald 1876:113 (partim: "Sikkim"). 
-Acanthosaura minor Boulenger 1885:304-305 (partim: "Afghanistan", "Khasia" \& "Sikkim").

Oriocalotes paulus Smith, 1935:166-167, 226.

Lectotype by present designation. Adult male, BMNH 1946.8.11.28 (previously BMNH xxiii.30.B), from "Affghanistan" (in error, likely to be Khasi Hills [in Meghalaya state, Northeast India], fide Günther 1864; type locality referred to as "Khasi Hills" by Smith 1935 without discussion), presented by the East India Company.

Paralectotypes by present designation. Adult male, BMNH 1946.8.11.27 (previously BMNH xxiii.30.A), and juvenile, BMNH 1946.8.11.29 (previously BMNH xxiii.30.C), from "Affghanistan" (see comment for lectotype), presented by the East India Company; adult male, BMNH 1946.8.11.35 (previously BMNH xxiii.30.D), from "Khassia hill", Meghalaya state, Northeast India, presented by the East India Company.

Additional material. Subadult female, NCBS-AQ197, and adult female, NCBS-AQ198, from Sohra (previously known as Cherrapunjee, $25^{\circ} 16^{\prime} 39.38^{\prime \prime} \mathrm{N}$; $91^{\circ} 41^{\prime} 48.95^{\prime \prime} \mathrm{E}, 1370 \mathrm{~m}$ a.s.1.), East Khasi Hills District, Meghalaya state, Northeast India, collected by Vivek Sarkar on 27 October 2014; an adult female and juvenile, BMNH 70.11.29.43, from 'Khassya', Meghalaya state, Northeast India, presented by T.C. Jerdon; adult male, BMNH 60.3.19.1378, from"Himalaya" (given as "Sikkim" [Northeast India] in Boulenger 1885]), collected by Messrs. von Schlagintweit; adult male, BMNH 72.4.17.328, and adult female, BMNH 72.4.17.329, from unknown localities (given as "Sikkim, [Northeast India] in Boulenger 1885]), presented by T.C. Jerdon; adult male, BMNH 60.3.19.1029, from "Afghan.?" (in error, likely to be "Khasya" [Meghalaya state, Northeast India], fide Günther 1864), presented by Dr. Griffith.

Diagnosis. A medium sized Calotes, snout to vent length averaging $57.5 \pm 12.5 \mathrm{~mm}$, and maximum to at least $71.0 \mathrm{~mm}$. Body feebly compressed with a weak dorsal crest; scales on top of head highly heterogeneous, keeled, those above orbits are largest, scales surrounding parietal are more or less similar in size; three spines on each side of head, one above orbit, one above tympanum and one on temporal region on each side; dorsal pholidosis heterogeneous, composed of medium sized, weakly pointed, strongly keeled scales intermixed with similar but slightly larger scales which are distinct on flanks; upper rows directed backwards and upwards and a few lower rows directed backwards; 42-46 midbody scale rows; a weakly developed fold anterior to forelimb insertion having granular scales; tympanum small, typically covered by a single large scale; tail rounded; seven to nine supralabials and seven to nine infralabials; lamellae bicarinate, 18-23 on fourth finger and 20-26 on fourth toe. Presence of heterogeneous scales on dorsum and weakly developed dorsal crest of Calotes paulus comb. nov. distinguish it from all known congeners.

Description of lectotype (BMNH 1946.8.11.28). Adult male. Mensural and meristic data is summarised in Table 2. General habitus slightly laterally compressed. Head relatively long (HL/SVL 0.32), broad (HW/HL ratio 0.66), not depressed (HD/HL ratio 0.55), slightly broader than neck (Fig. 5A). Snout short (SE/HL ratio 0.39), longer than orbital diameter (OD/SE ratio 0.85$)$. Orbit large (OD/HL ratio 0.33$)$; pupil round. Snout bluntly pointed in profile (Fig. $5 \mathrm{C}$ ), rostral rectangular, approximately two times longer $(1.8 \mathrm{~mm})$ than deep $(0.8 \mathrm{~mm})$, contacted by first supralabials and four scales dorsally. Nostril oval, laterally positioned, nasal large, pentagonal in shape, bordered by seven scales including supralabials one and two (Fig. 5C). Nine smooth rectangular supralabials, and seven infralabials. Loreal region slightly concave, scales of loreal region small, flat, dominated by a single row of enlarged scales extending from posterior edge of nasals, below orbits, to posteriormost supralabial on each side, enlarged scale row runs parallel with supralabials (though mostly separated from them by a single row of narrow scales; Fig. 5C). A row of four enlarged longitudinally keeled temporal scales extending from posterior edge of orbit to above anterior edge of tympanum. Orbital scales small, rounded, granular. Tympanum covered by a single scale (Fig. 5C). Canthals enlarged, overlapping slightly. Scales on dorsal surface of snout are heterogeneous in size and shape, smaller scales weakly tubercular, larger scales with distinct keels. Supraorbital scales weakly keeled, increase in size from supraciliaries to inner edges of orbits, of which enlarged scales follow curvature of orbits posterolaterally. Two small sized scale rows divide enlarged scales of inner orbits at narrowest point of frontal (Fig. 5B). Posterior mid-dorsal surface of the head (surrounding parietal scale) is dominated by a patch of slightly enlarged scales. Parietal scale moderately enlarged, longitudinally subrectangular without visible pineal eye (but with distinct depression) (Fig. 5B). Temporal spine longer than nuchal spines, orbital spine shorter, and supra-tympanic spine small (Fig. 5B). Mental subtriangular, approximately as wide as long, bordered posteriorly by a ventrolateral row of five elongated chin shields gradually changing shape and size posteriorly to blend with surrounding rows of gular scales. First pair of post-mental chin shields in contact laterally with infralabials, remaining shields are separated from infralabials by one to two rows of small gular scales (Fig. 5D). Remaining gular scales keeled (increasingly 

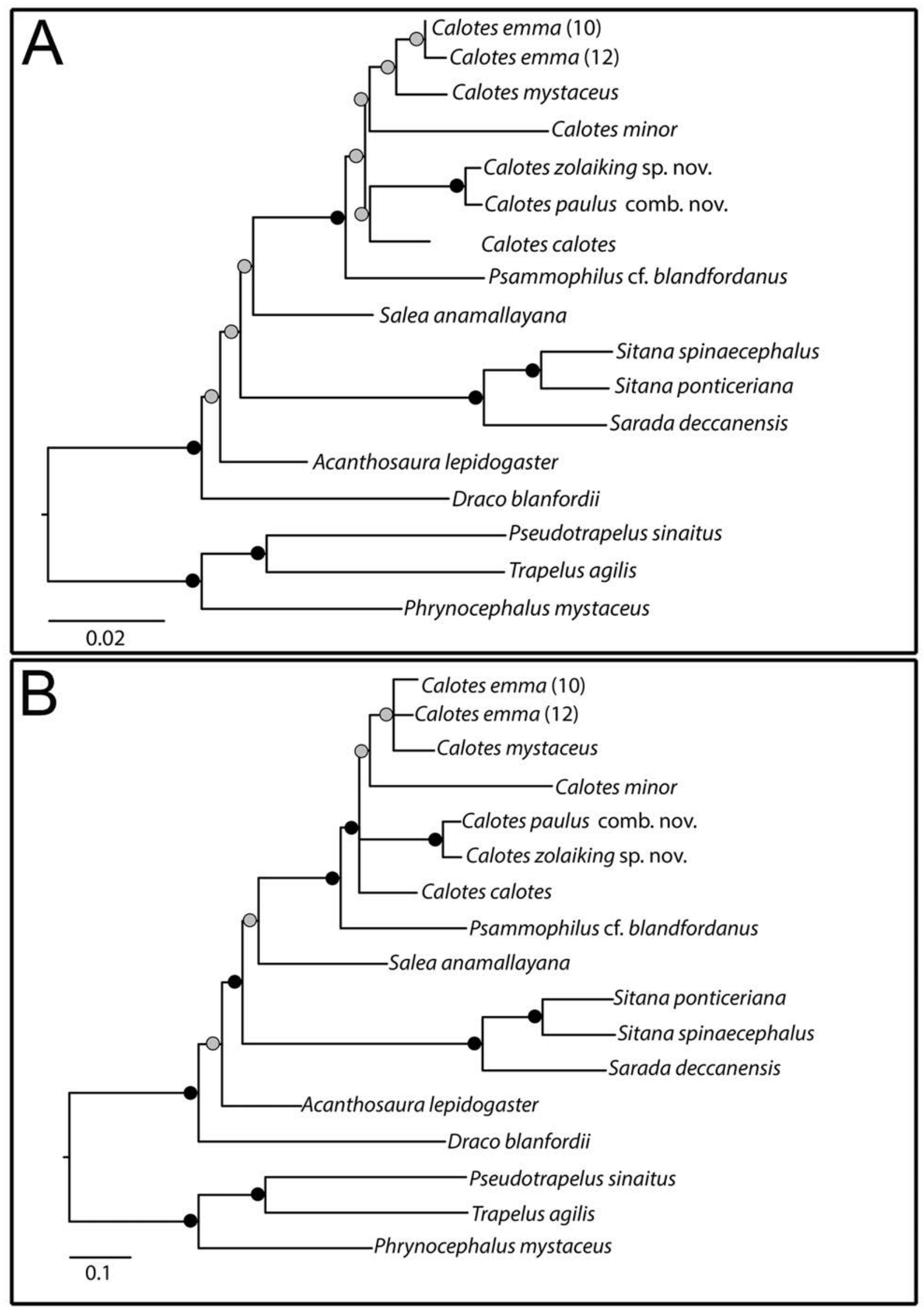

FIGURE 4. Phylogeny constructed using concatenated nuclear dataset (PTGER + R35+RAG1). A. ML phylogeny, bootstrap support: $>90$ dark circle; $<90$ grey circle. B. BI phylogeny, posterior probability: $>90$ dark circle; $<90$ grey circle. 
posteriorly), subimbricate, mid-gular scales smallest, increasing in size slightly posterolaterally and again decreasing in size dorsally over jowls. No distinct gular pouch present, and transverse gular fold absent (Fig. 5D). Ventral scales imbricate, strongly keeled, heterogeneous in size and arranged in approximate rows, 45 scales around mid-body. Nuchal crest is composed of nine short laterally compressed spines, largest on mid-nuchal region, decreasing in size anteriorly and posteriorly. Remaining vertebral scales are enlarged relative to adjacent rows, and possess a more pronounced median keel providing a serrated appearance in profile, 28 mid-dorsal scales in total. Dorsal and lateral scales are heterogeneous in size and shape (Fig. 5A), all scales with a moderate median keel, arranged into approximate rows, keels on those of upper flanks are mostly oriented obliquely upward, horizontal on mid-flanks, and obliquely downward on lower flanks. A distinct shallow oblique fold in front of and curving around anterior forelimb insertion (Fig. 5C). Scales of forelimbs and ventral hindlimbs form approximate rows, those of dorsal hindlimbs do not form regular rows and are heterogeneous in size. Dorsal scales larger than ventral scales on forelimbs and hindlimbs, all moderately keeled dorsally, and very weakly keeled ventrally. Forelimbs moderately long and thin (Fig. 5A); hindlimbs long and thin. Digits slender, each with a strong, slightly curved claw. Lamellae entire, bicarinate, 23 on fourth finger, and 26 on fourth toe. Tail rounded in cross section, approximately twice as long as SVL (TL/SVL ratio 1.98), slightly enlarged posterior to cloaca; scales on dorsal and ventral surfaces of tail are regularly arranged, strongly keeled, imbricate. Precloacal and femoral pores absent.

Coloration (in preservative). Dorsal surface of head mostly pale grayish/yellowish-brown with dark brown speckling on snout (Fig. 5B); lateral surfaces of snout pale grayish-white with brown blotches on lips; broad brown stripe extends from below eye to slightly posterior of tympanum (Fig. 5C). Dorsal and lateral surfaces of anterior two thirds of body pale grayish-brown, posterior half mostly dark brown mottled with pale grayish-brown (Fig. 5A). Dorsal surfaces of upper forelimbs pale grayish-brown, lower forelimbs mostly dark brown mottled with pale grayish-brown; dorsal surfaces of hindlimbs mottled light and dark brown (Fig. 5A). Tail primarily pale grayish-brown, with faint darker brown bands. Ventral surfaces of head, body and limbs pale grayish-white, with faint irregular stripes radiating from the central gular region (Fig. 5D).

Coloration in life (based on specimens not collected). Head, body, limbs and tail mostly mid to dark brown, with darker brown mottling, and occasionally green mottling. Area on lateral snout white, or white and green. Refer to Figure 6 for finer details of markings and coloration.

Variation. Most specimens examined correspond well with description of lectotype. Females generally larger in size (female SVL 57.9-71.3 mm, $N=4$ versus male SVL 55.5-66.6 mm, $N=5$ ). When hind limb is extended anteriorly along body, it typically reaches between posterior edge of tympanum and posterior edge of orbit on all specimens except BMNH 72.4.17.328 (reaches rear of jaw) and BMNH 72.4.17.329 (reaches anterior forelimb insertion). Transition from nuchal crest spines to strongly keeled dorsal scales is not clearly defined on some specimens (e.g., BMNH 72.4.17.328 and BMNH 60.3.19.1029). Tympanum covered by a single scale on all specimens, bar one (BMNH 60.3.19.137), which possess one to two rows of smaller scales bordering a single large scale anteriorly. Spinose scales in general poorly developed on juveniles. Finer details of coloration and markings vary between individuals, with some specimens having a distinct broad dark brown transverse cross bar on posterior half of dorsum. Further details of morphometric and meristic variation are presented in Table 2.

Suggested common name. Khasi Hills Forest Lizard.

Distribution and natural history. Calotes paulus comb. nov. is known with certainty only from the the Khasi Hills, Meghalaya state, Northeast India. The syntype series included three specimens with the associated collection locality "Affghanistan", which has been considered in error by several authors (e.g., Günther 1864; Boulenger 1885), and as such Afghanistan has been omitted from the distribution of the species by others (e.g., Anderson 1879; Smith 1935). Additional specimens in the NHMUK collected by T.C. Jerdon and the Schlagintweit brothers, have the associated collection locality "Sikkim". These collectors travelled to both the Darjeeling/Sikkim region and the Khasi Hills. Jerdon (1870) notes that he was aware that several of the localities given by the brothers Schlagintweit were erroneous "probably from the displacement of labels". Furthermore, collection localities associated with some of Jerdon's specimens from "Sikkim" have also been demonstrated to have been mislabeled for species otherwise found only in the Khasi Hills (Biju et al. 2016; Mahony et al. 2018). Jerdon (1870) also admits to not having seen this species, despite presenting specimens to the BMNH (NHMUK) soon after. By 1870, Jerdon had completed his tour to Sikkim, thus it is most likely that his specimens were collected from the Khasi Hills postscript. Smith (1935) clearly questioned Sikkim in the distribution of this species, as do we, since it has not been reported since these early specimens. References to the presence of this species in Xizang (Tibet), China by Zhao and Adler (1993) and Li et al. (2010, and references therein) require further confirmation. 

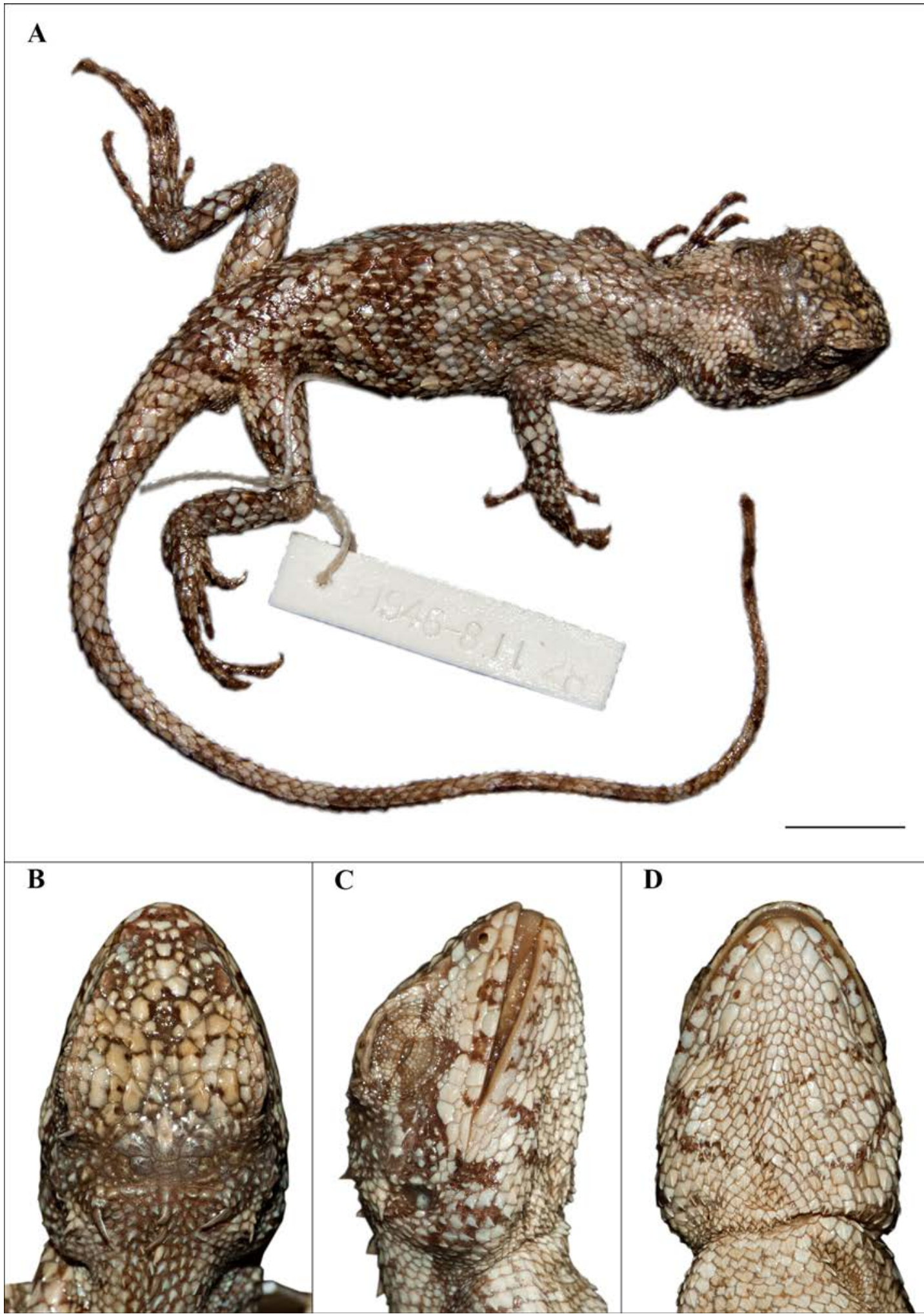

FIGURE 5. Lectotype of Calotes paulus comb. nov. (BMNH 1946.8.11.28). A. Dorsal view of body. B. dorsal view of head, C. lateral view of head, D. ventral view of head. Scale bar: $10 \mathrm{~mm}$.

Natural history observations of Calotes paulus comb. nov. were made by one of the authors (VS) over a period of one year at Sohra (previously known as Cherrapunjee), on the Shillong Plateau, East Khasi Hills District, Meghalaya state, Northeast India (Fig. 1). The remaining natural habitat in the vicinity of Sohra predominantly consists of grasslands with isolate trees and small patches of tropical moist evergreen forest (Champion \& Seth 1968) on hill slopes and around perennial hill streams (Fig. 7) Calotes paulus comb. nov. is one of the common agamids found 
in this area, where it has been observed along the fringes of forests, or on isolated tree trunks or large bushes. An adult female (BMNH 70.11.29.43) contained six large eggs (two measured, 14.1 X $8.2 \mathrm{~mm}$ and 14 X $8.5 \mathrm{~mm}$ ). One individual of Calotes paulus comb. nov. was observed feeding on a cicada (Gudaba sp.).

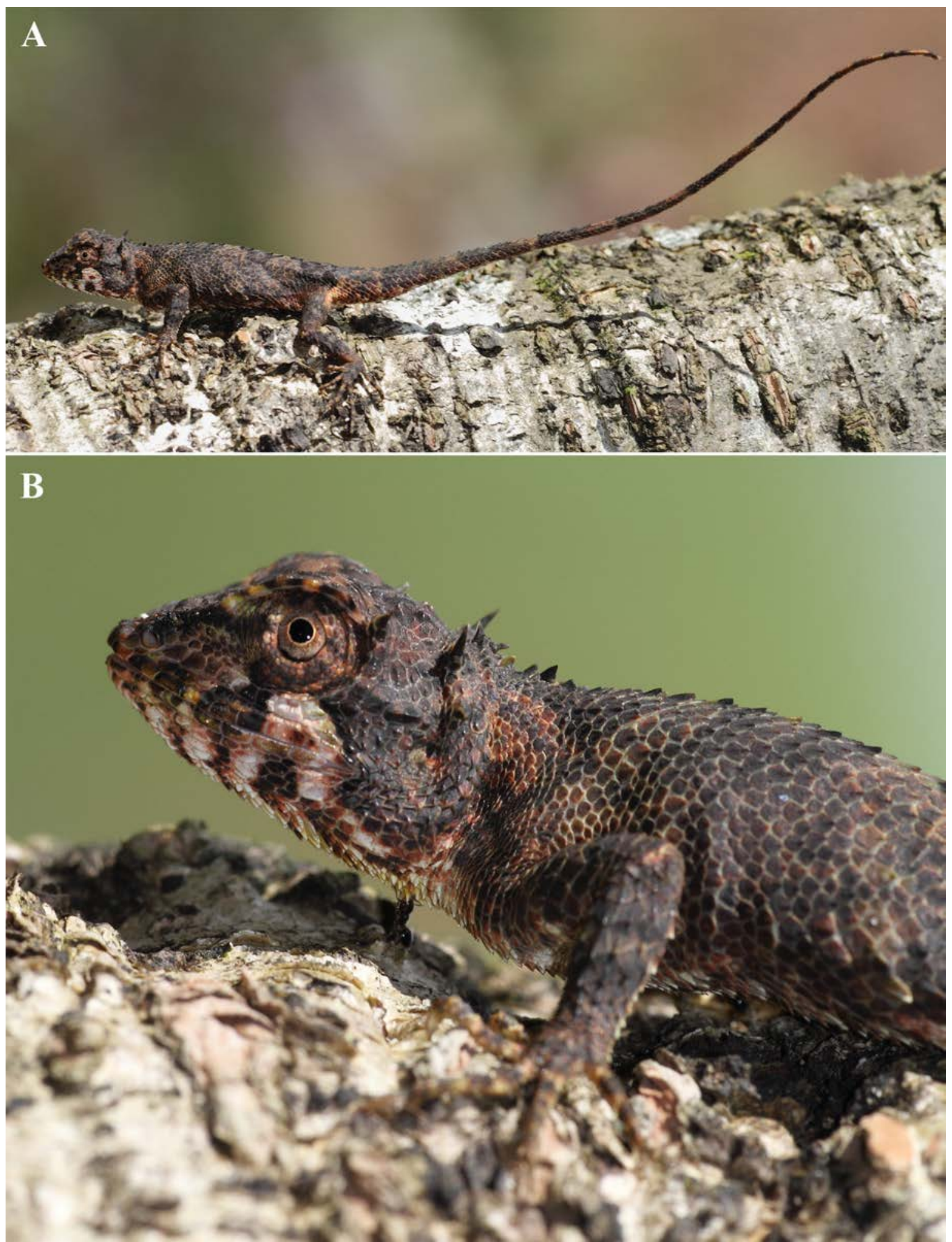

FIGURE 6. Calotes paulus comb. nov. showing live coloration, photographed in-situ from Sohra, East Khasi Hills District, Meghalaya state, Northeast India. 
TABLE 2. Morphometric measurements (in mm) of Calotes paulus comb. nov. specimen in the NHMUK. Refer to the Materials and methods section for morphometric and meristic abbreviations. NM: not mentioned; KH: Khasi Hills; HM: "Himalaya"; M: adult/ subadult male; F: adult/subadult female; J: juvenile unsexed; "-_" not assessed, ^ lectotype, * paralectotype

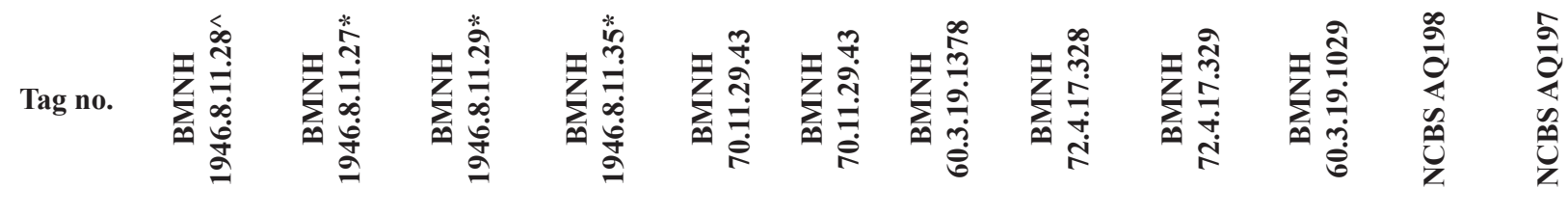

\begin{tabular}{|c|c|c|c|c|c|c|c|c|c|c|c|c|}
\hline Location & $\mathrm{KH}$ & $\mathrm{KH}$ & $\mathrm{KH}$ & $\mathrm{KH}$ & $\mathrm{KH}$ & $\mathrm{KH}$ & $\mathrm{HM}$ & NM & $\mathrm{NM}$ & $\mathrm{KH}$ & $\mathrm{KH}$ & $\mathrm{KH}$ \\
\hline Sex & M & M & $\mathrm{J}$ & M & $\mathrm{J}$ & F & M & M & M & M & $\mathrm{F}$ & FJ \\
\hline SVL & 58.8 & 56.8 & 28.3 & 58.3 & 39 & 69.4 & 62.1 & 66.6 & 71.3 & 55.5 & 66 & 57.9 \\
\hline $\operatorname{TrL}$ & 28.5 & 31.9 & 14.3 & 32.7 & 16.5 & 34.3 & 28.6 & 30.4 & 37.7 & 26.6 & 39 & 31.2 \\
\hline TL & 116.7 & 112.3 & 50.9 & 114.7 & 77 & 120 & 127 & 121.1 & 140.8 & 97.8 & 119 & 118.3 \\
\hline $\mathrm{TaD}$ & 3.8 & 3.9 & 1.9 & 3.9 & - & 4.9 & 5 & 5.6 & 6.2 & 4.5 & 5.4 & 4.5 \\
\hline TW & 4.1 & 4.5 & 2.1 & 4.8 & - & 5.6 & 5.6 & 6.5 & 5.6 & 5.1 & 5.2 & 4.5 \\
\hline HL & 19.1 & 18 & 10.3 & 19.3 & 13.5 & 20.2 & 19.8 & 20.3 & 22.7 & 18.4 & 19.5 & 17.2 \\
\hline HW & 12.7 & 12 & 7.7 & 13.3 & 9.2 & 14 & 13.8 & 13.8 & 14.7 & 12.7 & 14.3 & 11.5 \\
\hline HD & 10.6 & 10.4 & 6.4 & 10.5 & - & 11.7 & 11.6 & 11 & 11.7 & 10.1 & 11.5 & - \\
\hline SE & 7.5 & 6.8 & 4.2 & 7.4 & 5.1 & 8.2 & 7.8 & 7.6 & 8.5 & 6.5 & 7.1 & 5.9 \\
\hline $\mathrm{NE}$ & 4.6 & 3.8 & 2.5 & 4.3 & 3 & 5.2 & 4.9 & 4.5 & 5 & 3.9 & 4 & 4.3 \\
\hline $\mathrm{EE}$ & 4.3 & 4.1 & 2.5 & 4.4 & 3.3 & 5.1 & 4.9 & 5.1 & 4.9 & 3.4 & 4.7 & 4.1 \\
\hline IO & 8.1 & 7.7 & 4.8 & 7.6 & 5.9 & 8.7 & 8.6 & 8.6 & 9.8 & 7.5 & 9 & 7.5 \\
\hline SFI & 21.9 & 19.9 & 11.6 & 20.9 & 16.7 & 24.3 & 25.2 & 26.6 & 26.5 & 21.8 & 24.9 & 20.5 \\
\hline UAL & 8.6 & 8.2 & 3.9 & 7.9 & 6 & 9.4 & 8.9 & 9.4 & 9.4 & 9 & 11.8 & 11 \\
\hline LAL & 8.3 & 8.3 & 4.5 & 8.5 & 5.8 & 9.3 & 9.3 & 10.2 & 9.8 & 8.7 & 11 & 10 \\
\hline $\mathrm{HaL}$ & 13.2 & 12.7 & 6.8 & 11.2 & 8 & 13.6 & 12.5 & 12.1 & 11.5 & 10.4 & 12 & 11.3 \\
\hline $4 \mathrm{FL}$ & 9.5 & 8.3 & 4.2 & 7.3 & 4.8 & 8.8 & 8.1 & 8.2 & 7.7 & 6.7 & 8.4 & 8.2 \\
\hline ULL & 11.3 & 12.1 & 6.7 & 12 & 8.4 & 13.2 & 13 & 13.2 & 13.1 & 12.6 & 13.5 & 12.3 \\
\hline LLL & 10.9 & 11.6 & 6.2 & 11.3 & 7.9 & 13 & 12.5 & 13.1 & 13.1 & 11.9 & 12.7 & 12.9 \\
\hline FOL & 18.1 & 17.3 & 9.6 & 17.6 & 12.5 & 20.6 & 18.3 & 19 & 18.7 & 17.2 & 18.2 & 17 \\
\hline $4 \mathrm{TL}$ & 16.1 & 14.9 & 5.5 & 13.3 & 10.4 & 16.3 & 15.3 & 15.1 & 15.4 & 14.1 & 10.7 & 10.7 \\
\hline TD & 1.9 & 1.8 & 1.1 & 1.5 & 1.3 & 1.8 & 2.1 & 1.8 & 2.1 & 2.1 & 1.3 & 1.6 \\
\hline OD & 6.4 & 6.3 & 3.9 & 6.5 & 4.8 & 7 & 6.4 & 6.4 & 7.5 & 6.1 & 6.4 & 5.8 \\
\hline $\mathrm{SnS}$ & 9 & 9 & 13 & 11 & 11 & 11 & 11 & 12 & 12 & 10 & 7 & 9 \\
\hline HeadSTr & 13 & 12 & 14 & 13 & 12 & 11 & 12 & 14 & 14 & 11 & 12 & 14 \\
\hline $\mathrm{CS}$ & 6 & 5 & 5 & 5 & 6 & 6 & 5 & 5 & 5 & 5 & 5 & 7 \\
\hline $\mathrm{SL}(\mathrm{L} / \mathrm{R})$ & 9/- & $8 /-$ & $8 /-$ & $7 /-$ & $8 /-$ & 9/- & $7 /-$ & $8 / 8$ & $7 / 8$ & $8 / 8$ & $7 / 8$ & $8 / 8$ \\
\hline $\mathrm{IL}(\mathrm{L} / \mathrm{R})$ & $7 /-$ & $8 /-$ & $7 /-$ & $8 /-$ & $8 /-$ & $9 /-$ & 9/- & $8 / 8$ & $8 / 8$ & $8 / 8$ & $8 / 8$ & $8 / 8$ \\
\hline $\mathrm{NC}$ & 9 & 6 & - & 6 & - & 5 & 10 & - & 6 & - & 6 & 4 \\
\hline VS & 28 & 29 & 27 & 30 & 24 & 31 & 28 & 31 & 32 & 31 & 28 & 29 \\
\hline MSR & 45 & 42 & 45 & 44 & 44 & 44 & 45 & 46 & 46 & 43 & 44 & 46 \\
\hline 4Flam & 23 & 21 & 19 & 18 & 22 & 21 & 23 & 21 & 21 & 19 & 20 & 23 \\
\hline 4TLam & 26 & 22 & 20 & 21 & 25 & 24 & 24 & 26 & 23 & 23 & 27 & 27 \\
\hline
\end{tabular}


Calotes zolaiking sp. nov.

Figs 8-12; Tables 3-5.

Holotype. Adult female, NCBS-AU152, from Synod Hospital Compound (2346 $19.06^{\prime \prime} \mathrm{N}, 92^{\circ} 43^{\prime} 56.37^{\prime \prime} \mathrm{E}, 1290$ $m$ a.s.1.), Durtlang, Aizawl District, Mizoram state, Northeast India, collected by C. Lalrinchhana and Samuel Lalrounga on 10 June 2014.

Paratypes. Two subadult females, NCBS-AU153 and ESV 105, an adult female, NCBS-AU154, and a subadult male, NCBS-AU155, collection data same as holotype; subadult male, BNHS 2327, from Hmuifang $\left(23^{\circ} 27^{\prime} 17.93^{\prime \prime} \mathrm{N}\right.$, $92^{\circ} 45^{\prime} 07.05^{\prime \prime} \mathrm{E}, 1478 \mathrm{~m}$ a.s.1.), Aizawl District, Mizoram state, Northeast India, collected by C. Lalrinchhana and Samuel Lalrounga.

Referred specimens. Adult male, NCBS-AU156 collection data same as holotype.

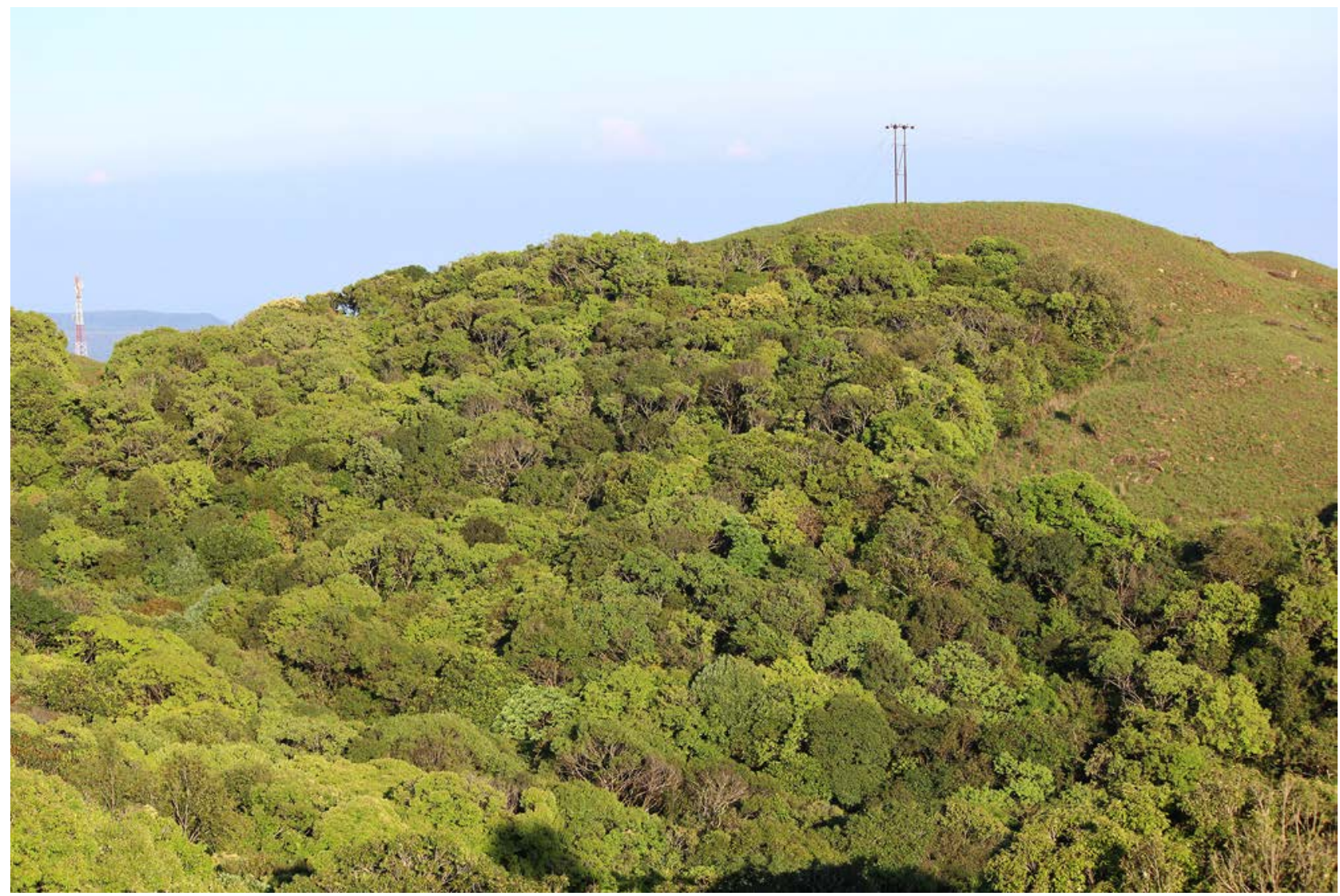

FIGURE 7. Habitat where Calotes paulus comb. nov. were found in Sohra, East Khasi Hills District, Meghalaya state, Northeast India.

Diagnosis. A medium sized Calotes, snout to vent length averaging $64.7 \pm 8.17$, and maximum to at least $77.0 \mathrm{~mm}$. Body feebly compressed laterally with a weak dorsal crest; scales on top of head highly heterogeneous, keeled, those above orbits are largest, scales surrounding parietal are unequal in size; three spines on each side of head, one above orbit, one above tympanum and one on temporal region; dorsal scales heterogeneous, composed of medium sized, weakly pointed, strongly keeled scales, intermixed with similar but slightly larger scales which are distinct on flanks, upper rows directed backwards and upwards and a few lower rows directed backwards; 49-52 midbody scale rows; a weakly developed fold anterior to forelimb insertion having granular scales; tympanum small; tail rounded; eight to nine supralabials and seven to ten infralabials; lamellae bicarinate, 21-24 on fourth finger and 23-27 on fourth toe.

Calotes zolaiking sp. nov can be easily diagnosed from all congeners except Calotes paulus comb. nov. in possessing heterogeneous scales on the dorsum and a weakly developed dorsal crest. Based on dorsal pholidosis, the new species is most similar to Calotes paulus comb. nov., but differs with respect to the following (Calotes paulus comb. nov. given in parentheses): greater number of midbody scales rows, 49-52 (versus 42-46), greater number of caudal vertebrae, 50 (versus 35-45), and fewer caudal vertebrae with transverse processes 12 (versus 14).

Description of holotype (NCBS-AU152). Specimen is generally in good condition but slightly dehydrated, tail bent toward left in a sigmoid manner, left manus slightly adpressed with outer three fingers curved, right manus ad- 
pressed with fingers directed backwards, eyes sunken, orbital spine on left side broken, tips of supra-tympanic spines on both sides curved, all artefacts of preservation. Mensural and meristic data is summarised in Table 3. An adult female, SVL $77.2 \mathrm{~mm}$. Head relatively long (HL/SVL 0.31), broad (HW/HL ratio 0.65), not depressed (HH/HL ratio 0.52 ), noticeably broader than neck (Fig. 8A). Snout short (SE/HL ratio 0.37 ), longer than orbit diameter (OD/SE ratio 0.78). Orbit large (OD/HL ratio 0.29); pupil round, eyelids covered with small rounded scales, a single row of scales bordering eyelids slightly elongate, six supraciliaries on each side, elongate, subimbricate, slightly protruding laterally on supraorbital ridge, similar in size, with single anterior most supraciliary smallest. Snout obtusely pointed; rostral wider $(2.1 \mathrm{~mm})$ than deep $(0.7 \mathrm{~mm})$, contacted laterally by first supralabial, an elongated large prenasal, and two large scales dorsally. Canthus rostralis and supraciliary edge sharp. Nostril circular, laterally positioned and placed at centre of a large, undivided nasal plate (Fig. 8C), which is bordered by seven scales on both sides, including one prenasal, one supranasal, three postnasals, with two subnasals on left side, and one subnasal and second supralabial on right side; separated on both sides from rostral and first supralabial by prenasal. Supralabials roughly rectangular, more or less equal sized, posterior-most being longest, bordered above by two rows of scales starting behind postnasals and extending to posterior border of orbit; upper row distinctly enlarged consisting of equal sized, roughly rectangular scales; scales on lower row are heterogeneous in shape and size, decreasing in size posteriorly. Loreal region concave, scales of loreal region heterogeneous in shape and size, flat or weakly tuberculate. Scales on postorbital and temporal region heterogeneous in shape and size, subimbricate, mostly tuberculate; a row of five much larger longitudinally keeled scales, fourth being largest, extending from posterior midorbital region to just before anterior edge of tympanum (Fig. 8C). Tympanum covered with single scale (Fig. 8C). Canthals enlarged, overlapping, becoming slightly larger along supraciliaries. Scales on dorsal surface of snout and forehead heterogeneous in shape and size, all weakly pointed anteriorly (Fig. 8B), smaller scales weakly tubercular, larger with distinct keels except those on internarial region which are roughly rounded, uniformly large and smooth. Supraorbital scales weakly keeled, increase in size from supraciliaries to inner edges of orbits, of which enlarged scales follow curvature of orbits posterolaterally (Fig. 8B). Two small scale rows divide enlarged scales of inner orbits at narrowest point of frontal. Scales on occipital region heterogeneous in shape and size; smaller scales weakly tubercular, larger ones with distinct keels. Parietal scale roughly triangular, without visible pineal eye (but with distinct depression) (Fig. 8B). Parietal scale bordered laterally by three enlarged, roughly elongated keeled scales, with much smaller scales anteriorly and posteriorly. Single temporal spine on each side, longer than nuchal spines; shorter orbital spine and a small supra-tympanic spine also present on each side (Fig. 8B). Mental subtriangular, approximately as wide as long, bordered posterolaterally by a row of six elongated postmental chin shields on either side, gradually changing shape and size posteriorly to blend with surrounding rows of gular scales (Fig. 8D). First pair of postmental chin shields in contact laterally with first infralabials, remaining shields separated from infralabials by one to two rows of small gular scales. Posterior gular region with considerably enlarged, flat, strongly keeled, pointed, imbricate scales, those on jowls slightly larger in size; anterior gular scales much smaller, rounded, weakly keeled and subimbricate; all gular scales directed posteromedially except a few median rows which are directed posteriorly. No distinct gular pouch present, transverse gular fold absent (Fig. 8D). Ventral scales are like those on posterior gular region, enlarged, flat, strongly keeled, pointed, imbricate, homogenous in shape but heterogeneous in size, generally increasing in size laterally; arranged in regular longitudinal rows that are directed posteriorly, but those on lateral aspect are directed posteromedially (Fig. 9C). Approximately 49 scales around mid-body. Nuchal crest composed of three short, laterally compressed, equal sized spines. Remaining vertebral scales slightly enlarged relative to adjacent rows (Fig. 9A) but possess a more pronounced median keel providing a serrated appearance in profile (Fig. 9B); 33 mid-dorsal scales from first raised nuchal scale to above level of cloaca. Dorsal scales heterogeneous in size and shape; all scales with a moderate median keel, arranged into approximate rows (Fig. 9A \& B); keels on those of upper flanks mostly oriented obliquely upward, horizontal on mid-flanks and obliquely downward on lower flanks (Fig. 9B). A distinct shallow oblique fold in front, and curving around anterior forelimb insertion. Scales of forelimbs and ventral hindlimbs form approximate rows, those on dorsal hindlimbs do not form regular rows and are heterogeneous in size. Dorsal scales larger than ventral scales on forelimbs and hindlimbs, all moderately keeled dorsally, very weakly keeled ventrally. Forelimbs moderately long (UAL+LAL+HaL/SVL ratio 0.45); hindlimbs long (ULL+LLL+FoL/SVL ratio 0.66). Digits slender, elongate and ending in a strong, slightly curved claw. Lamellae entire, bicarinate; 21 on fourth finger, 23 on fourth toe. Relative finger lengths: $\operatorname{IV}(8.5 \mathrm{~mm})>\operatorname{III}(7.9 \mathrm{~mm})>\operatorname{II}(4.6 \mathrm{~mm})$ $>\mathrm{V}(4.1 \mathrm{~mm})>\mathrm{I}(3.0 \mathrm{~mm})$ and toes $\operatorname{IV}(11.9 \mathrm{~mm})>\mathrm{III}(10.5 \mathrm{~mm})>\mathrm{V}(8.2 \mathrm{~mm})>\mathrm{II}(7.2 \mathrm{~mm})>\mathrm{I}(5.5 \mathrm{~mm})$. Tail entire, rounded, nearly twice head-body length (TL/SVL ratio 1.87), not swollen at base (Fig. 8A); uniformly covered with similar sized, strongly keeled, weakly pointed, regularly arranged, posteriorly directed imbricate scales. 

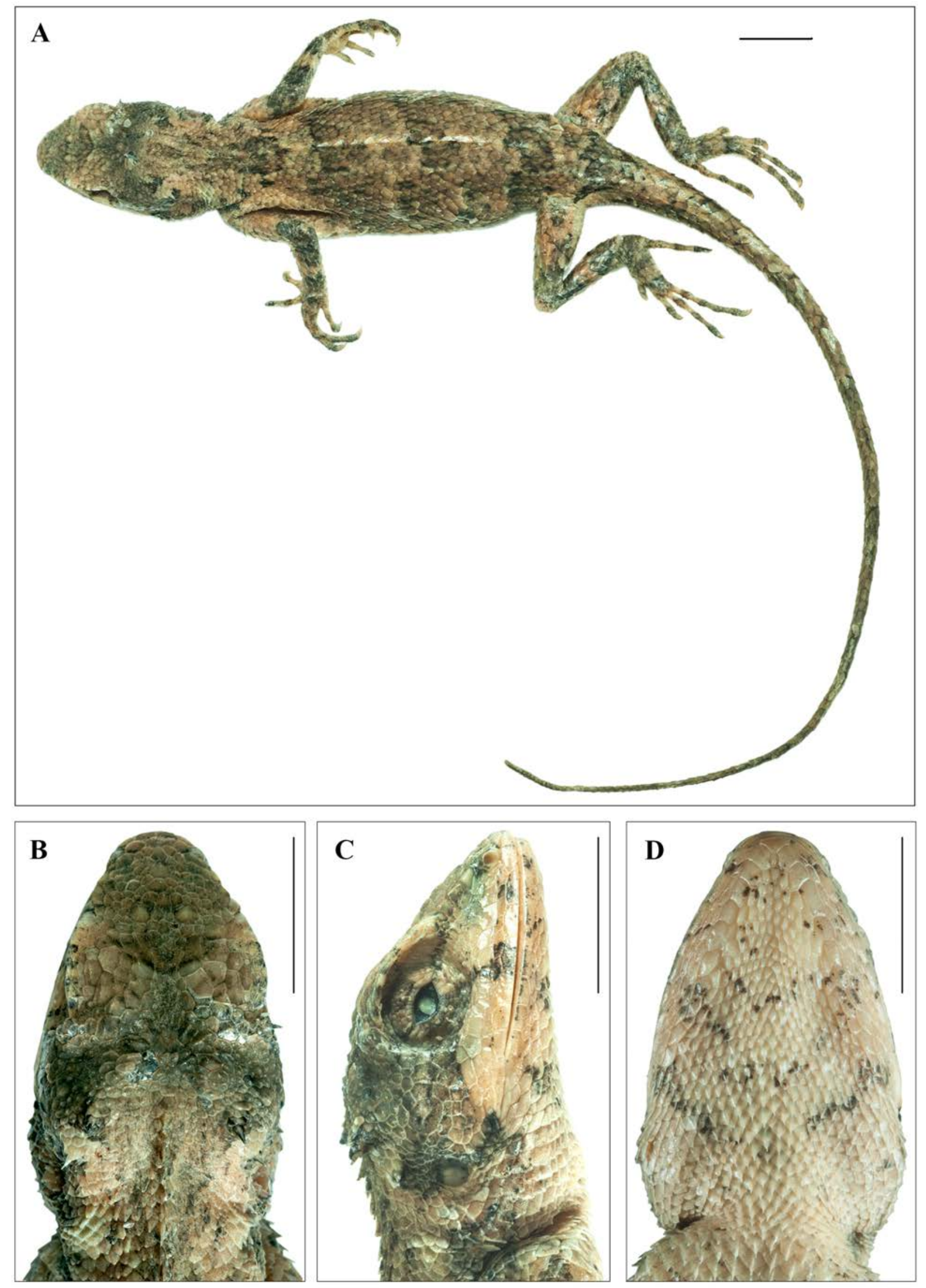

FIGURE 8. Holotype of Calotes zolaiking sp. nov. (NCBS-AU152). A. Dorsal view, B. dorsal view of head, C. lateral view of head, D. ventral view of head. Scale bar: $10 \mathrm{~mm}$. 

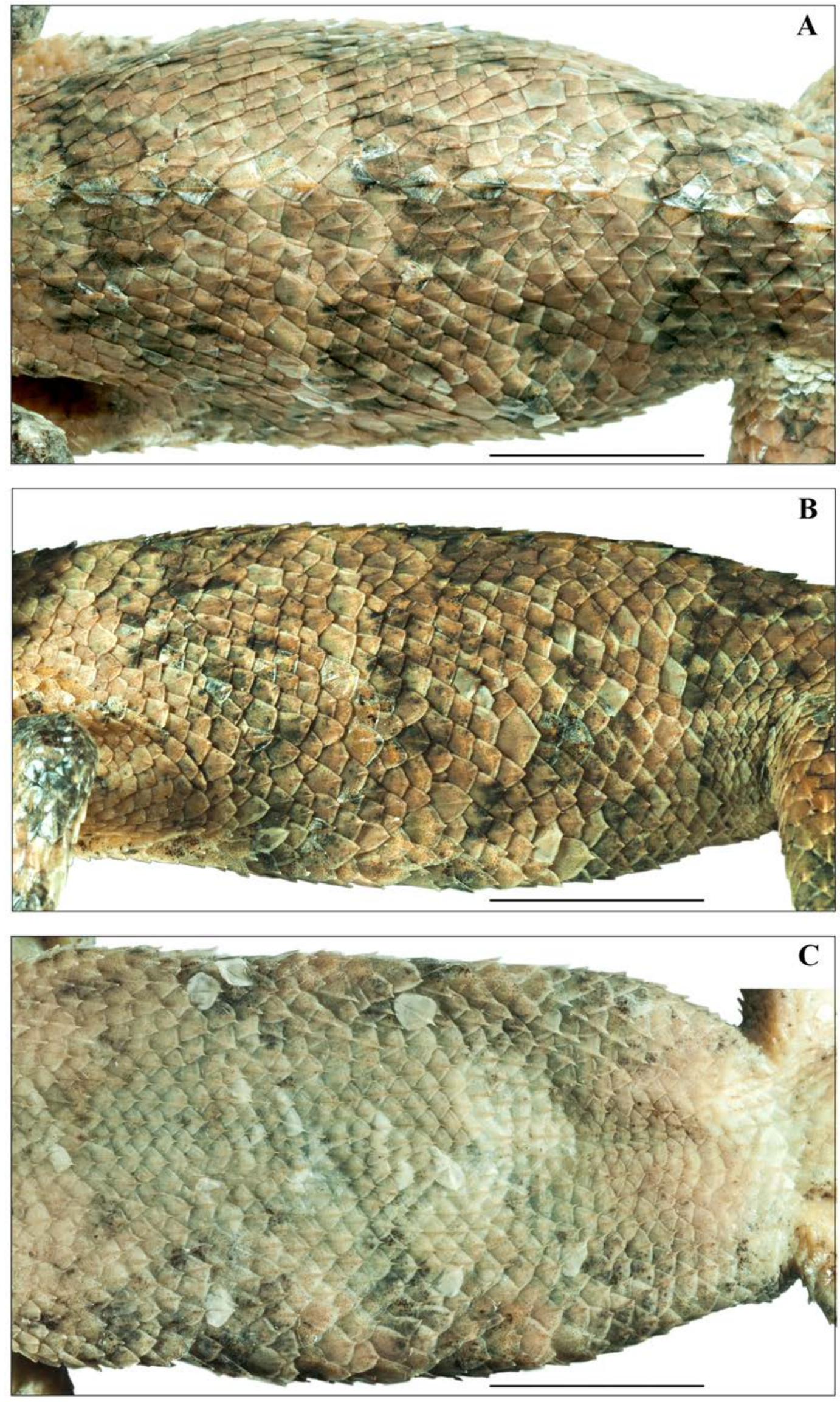

FIGURE 9. Scales on trunk of holotype of Calotes zolaiking sp. nov. (NCBS-AU152). A. Dorsal view, B. lateral view, C. ventral view. 


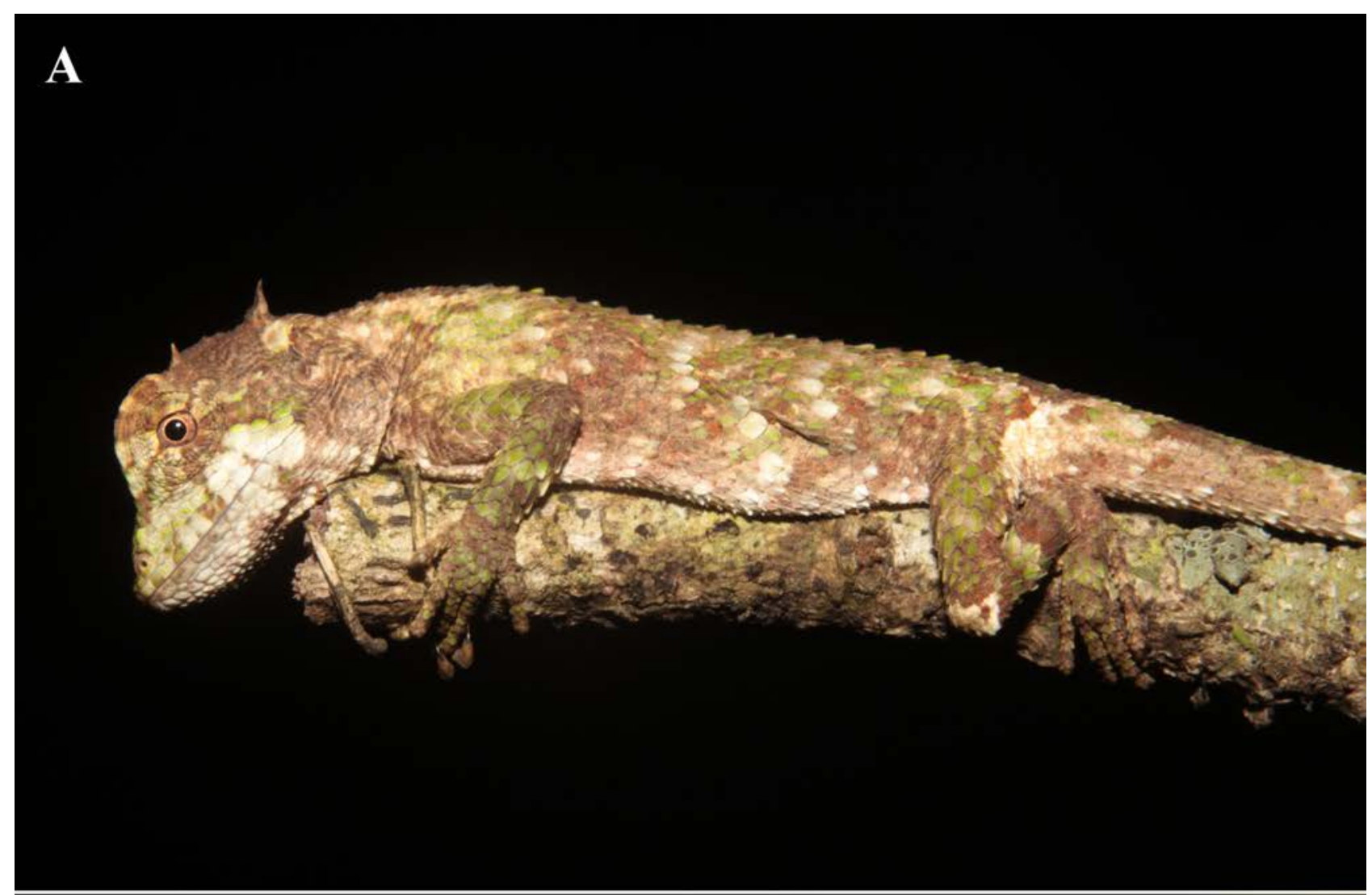

B

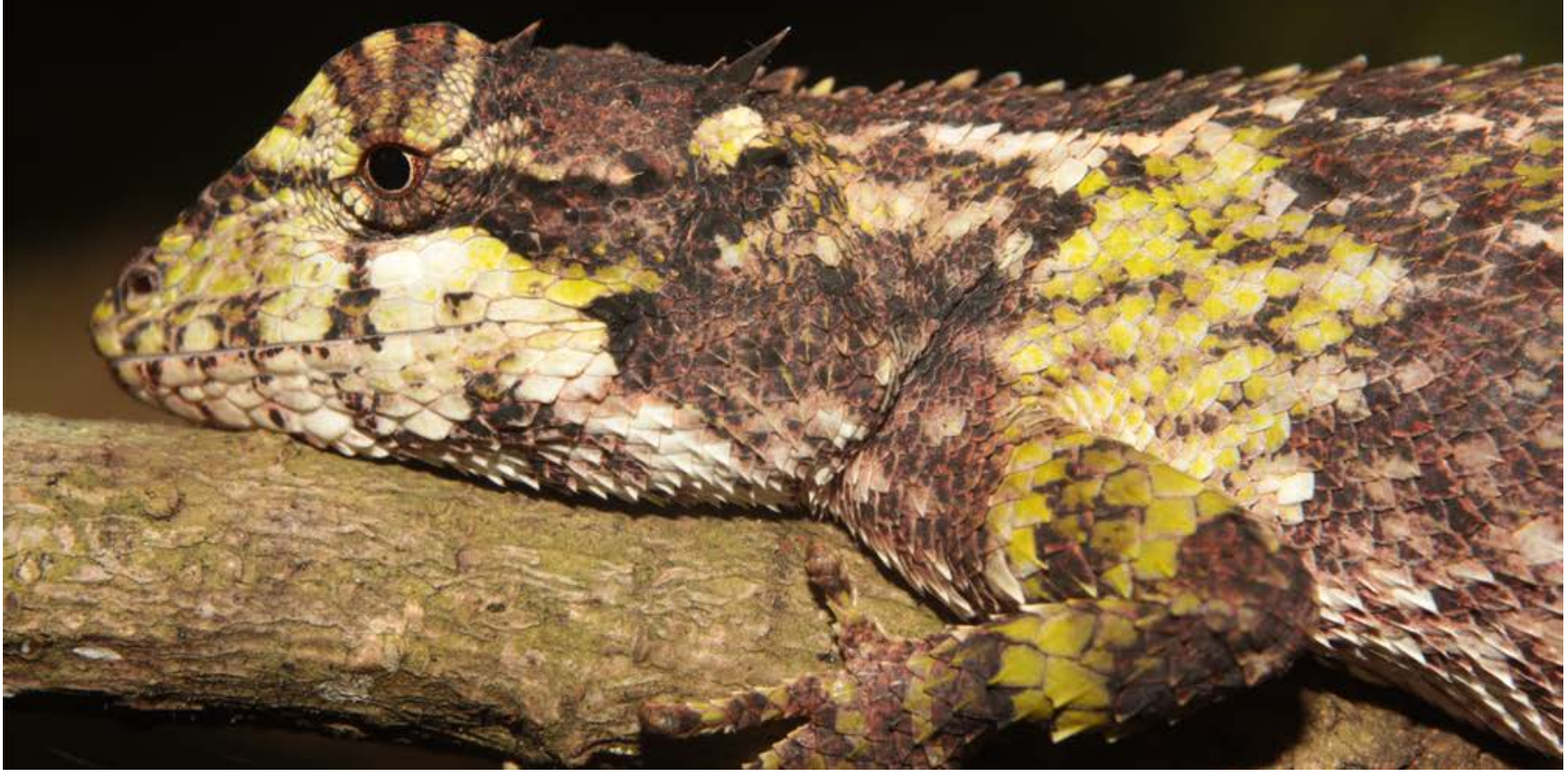

FIGURE 10. Calotes zolaiking sp. nov. showing live coloration, photographed in-situ from Durtlang, Aizawl District, Mizoram state, Northeast India. 
TABLE 3. Morphometric measurements (in mm) of Calotes zolaiking sp. nov. Refer to the Materials and methods section for morphometric and meristic abbreviations. M: adult/subadult male; F: adult/subadult female; MJ: juvenile male; * tail broken; ^ holotype, \# paratype, †referred material

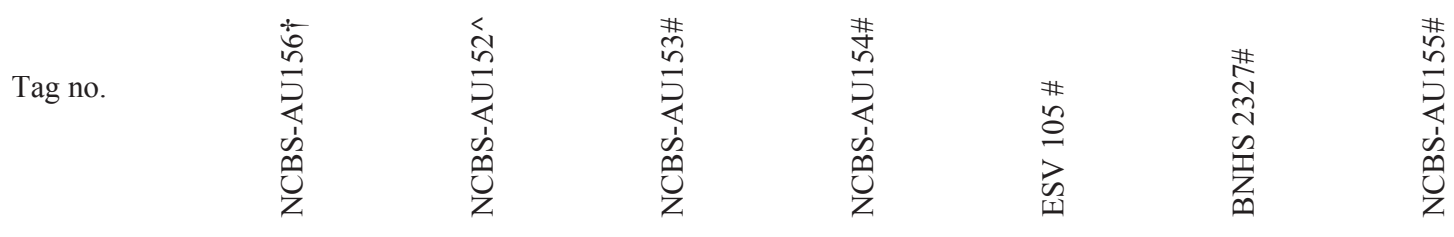

\begin{tabular}{|c|c|c|c|c|c|c|c|}
\hline Location & Mizoram & Mizoram & Mizoram & Mizoram & Mizoram & Mizoram & Mizoram \\
\hline Sex(maturity) & M & $\mathrm{F}$ & $\mathrm{F}$ & $\mathrm{F}$ & $\mathrm{F}$ & MJ & MJ \\
\hline SVL & 62.9 & 77.2 & 71.2 & 68.6 & 62.2 & 52.9 & 58.5 \\
\hline $\operatorname{TrL}$ & 33.5 & 42.7 & 40.4 & 36.7 & 32.3 & 27.4 & 29.7 \\
\hline $\mathrm{TL}$ & 122.1 & 145.1 & $123.5^{*}$ & 129.2 & $112.5^{*}$ & 118.6 & 120 \\
\hline $\mathrm{TaD}$ & 6 & 6.2 & 5.4 & 4.7 & 4.2 & 4.6 & 5.1 \\
\hline TW & 7.6 & 6 & 4.7 & 5.1 & 4.4 & 5.4 & 5.9 \\
\hline HL & 18.4 & 23.8 & 21.2 & 20.2 & 18.5 & 16.5 & 17.7 \\
\hline HW & 11.8 & 15.6 & 13.6 & 13.4 & 12.2 & 11 & 11.7 \\
\hline HD & 10.9 & 12.6 & 11.5 & 11 & 10.8 & 9.1 & 10 \\
\hline SE & 7.1 & 8.9 & 8.3 & 7.7 & 7.4 & 6.1 & 6.5 \\
\hline $\mathrm{NE}$ & 4.3 & 6.5 & 5.4 & 4.5 & 4.4 & 3.8 & 4.1 \\
\hline $\mathrm{EE}$ & 4.2 & 6.2 & 5 & 5 & 4.1 & 3.7 & 4 \\
\hline $\mathrm{IO}$ & 7.5 & 10 & 9.6 & 8.8 & 8 & 7.1 & 8.1 \\
\hline SFI & 23.7 & 27.1 & 21.5 & 23.5 & 23.5 & 19.6 & 21.4 \\
\hline UAL & 8.5 & 12.2 & 9.5 & 11.8 & 10.4 & 9.3 & 10.9 \\
\hline LAL & 8.8 & 9.7 & 9.3 & 9.5 & 9.5 & 7.9 & 9.2 \\
\hline $\mathrm{HaL}$ & 9.7 & 13.6 & 12.3 & 11.5 & 10.2 & 9.4 & 10.5 \\
\hline $4 \mathrm{FL}$ & 7.1 & 8.5 & 8.4 & 7.4 & 7.2 & 6.7 & 8.1 \\
\hline ULL & 13.2 & 16.7 & 14.1 & 13.4 & 12.6 & 10.7 & 13.1 \\
\hline LLL & 10.9 & 15.6 & 13.5 & 12.6 & 12.5 & 11.1 & 11.6 \\
\hline FOL & 16.8 & 19.4 & 18.5 & 17.6 & 14 & 13.5 & 16.4 \\
\hline $4 \mathrm{TL}$ & 9.8 & 11.9 & 11.1 & 10.4 & 9.9 & 8.7 & 10.6 \\
\hline TD & 1.6 & 2 & 1.3 & 1.5 & 1.5 & 1 & 1.2 \\
\hline OD & 5.7 & 7 & 6.5 & 6.2 & 6 & 6 & 6.1 \\
\hline $\mathrm{SnS}$ & 11 & 12 & 11 & 10 & 8 & 9 & 11 \\
\hline HeadSTr & 13 & 15 & 14 & 15 & 13 & 12 & 16 \\
\hline $\mathrm{CS}$ & 5 & 6 & 6 & 7 & 5 & 6 & 7 \\
\hline $\mathrm{SL}(\mathrm{L} / \mathrm{R})$ & $8 / 8$ & $8 / 9$ & $8 / 9$ & $8 / 8$ & $8 / 8$ & $9 / 8$ & $9 / 8$ \\
\hline $\mathrm{IL}(\mathrm{L} / \mathrm{R})$ & $9 / 9$ & $9 / 9$ & $9 / 10$ & $10 / 10$ & $7 / 7$ & $9 / 8$ & $8 / 8$ \\
\hline $\mathrm{NC}$ & 3 & 3 & 3 & 7 & 5 & 4 & 2 \\
\hline VS & 32 & 33 & 32 & 33 & 34 & 35 & 34 \\
\hline MSR & 49 & 49 & 50 & 52 & 51 & 50 & 49 \\
\hline 4Flam & 24 & 21 & 23 & 24 & 23 & 22 & 24 \\
\hline 4TLam & 26 & 23 & 25 & 27 & 26 & 26 & 26 \\
\hline
\end{tabular}


Coloration (in preservative). Coloration in preservation is more or less similar to live specimens but slightly faded and predominantly light brown. Transverse stripes on body, limbs and tail are darker. Refer to Figures 8 and 9 for further details of coloration and markings.

Coloration in life (based on specimens other than the holotype). Coloration in life varies, but is primarily mottled shades of light and darker brown dorsally, with four distinct lighter transverse stripes on body, two on forelimbs and two on hindlimbs; stripes may be primarily green or light brown (Fig. 10). Two thin white longitudinal stripes on upper flanks extend from rear of head to base of tail. Region below orbit and lateral surface of snout white, with narrow white and brown radial stripes extending from eye. Tail with faint light and darker brown bands. Ventral surfaces whitish, throat with irregularly arranged dark mottling or thin stripes. Refer to Figure 10 for further details of coloration and marking on live animals.

Variation. Paratypes and referred specimen agree with holotype in general morphology and scalation with following exceptions: NCBS-AQ154 has ten infralabials on both sides, and ESV 105 has seven infralabials on both sides; 35 vertebral scales on BNHS 2327; within paratype series, lamellae on fourth finger varies from 22 to 24 , and on fourth toe from 25 to 27. Further variation in mensural and meristic characters within paratype series is documented in Table 3.

Hemipenis. Hemipenis single, clavate (divided less than half of length) with length of organ greater than width. Base naked; sulcus spermaticus broad, canal like, shallow at base and deeper at terminal region. Lips of sulcus spermaticus smooth. Calyculate ornamentation present on each lobe. Thick walled smooth calyces form deep oval pits. Fleshy cardioid structure at base of ventral sulcus absent. Apex capitate and divided into four segments (Fig. 11). Hemipenis of Calotes zolaiking sp. nov. matches with 13 out of 14 characters reported for seven other Calotes spp., and 12 out of 14 characters reported for Calotes ceylonensis Müller, 1887 (Maduwage et al. 2008; Table 4).

Osteology. Skull of Calotes zolaiking sp. nov. (NCBS-AU156) is subpentagonal in outline (Fig. 12A): raised in parietal region and slopes steeply towards naris (Fig. 12B). Hyoid apparatus broad with a paired ceratobranchial (CB), CB II shorter than CB I. Maxilla has 14 teeth (including one canine-like tooth [on each side]); three premaxillary teeth; thirteen teeth on either side of mandibles (Fig. 12D \& E). Twenty presacral vertebrae excluding atlas and axis and 50 caudal vertebrae (Table 5). Sternum with an oval and elongated central foramen. Ten trunk vertebrae have ribs, and an additional five vertebrae near pelvic girdle have ribs replaced by small transverse processes. Shoulder girdle comprises a broad clavicle; interclavicle long and rod like, suprascapula wedge shaped. Humerus with well-developed proximal and distal ends. Phalangeal formula of manus is 2:3:4:5:3 and of pes is 2:3:4:5:4. Many osteological characters checked for Calotes zolaiking sp. nov. (NCBS-AU156) matched those of Calotes paulus comb. nov., except the former had a higher number of caudal vertebrae (Table 5). Calotes paulus comb. nov. and Calotes zolaiking sp. nov. differ from other congeners in five different osteological characters (Table 5). Calotes paulus comb. nov. and Calotes zolaiking sp. nov. differ from Pseudocalotes in three different osteological characters (Table 5). Within the genera Calotes and Pseudocalotes, there are several variable characters (Table 5).

Etymology. The species is named for its occurrence in high elevation regions. The specific epithet is a noun in apposition, derived from the Mizo language and is a portmanteau word for a lizard that inhabits high elevations (Mizo: $\mathrm{Zo}=$ highland/cold region, Laiking = agamid lizard).

Suggested English name. Mizoram Montane Forest Lizard.

Distribution and natural history. Calotes zolaiking sp. nov. is known only from its type and paratype localities, Durtlang (1290 m a.s.1.) and Hmuifang forest (1480 m a.s.l.) in Aizawl District, Mizoram state, Northeast India. These two localities are approximately $36 \mathrm{~km}$ apart [straight line distance]. This species is also suspected to be found in other high elevation areas of Mizoram. However, very few herpetological surveys have been carried out in this state, so the full extent of its distribution and preferred elevational range is currently unknown. The holotype was collected from a residential area where both native and non-native trees were present. It was seen perching on a Melaleuca citrina (Curtis) Dum.Cours. (bottlebrush tree), an introduced ornamental species native to Australia. The native trees dominating the locality include Trema orientalis Blume, Callicarpa arborea Roxb., Schima wallichii (DC.) Korth., Castanopsis tribuloides Sm., Albizia chinensis (Osbeck) Merr. and Ficus semicordata Buch.-Ham. ex Sm. The locality where the paratypes were collected is dominated by Rapanea capitellata (Wall) Mez., a Eurya sp. Korth., Quercus spp. L., Elaeocarpus rugosus Roxb., Nyssa javanica (Blume) Koord., a Macropanax sp. Miq., Schima wallichii (DC.) Korth. and Ardisia macrocarpa Wall., with a small patch of grassland (Fig. 13). According to Champion and Seth (1968), these regions fall under their "Montane Sub-tropical Forest" category. Most of the natural history observations of Calotes zolaiking sp. nov. were made from Hmuifang where the paratypes were collected. The type series was collected from vegetation at a height of 1.5-4.5 m above ground level. All individuals of 
the species were spotted perching on branches, which suggests they are primarily arboreal. In captivity, an adult female (NCBS AU154) laid three large eggs (measuring $14.1 \times 8.2 \mathrm{~mm}, 14.3 \times 8.5 \mathrm{~mm}$ and $14.5 \times 8.5 \mathrm{~mm}$ ) in July. During fieldwork at the type locality, juveniles were observed in November. Other agamids found in sympatry include Calotes cf. versicolor and Cristidorsa otai (Mahony, 2009).

Phylogenetic relationships and morphology. Based on its phylogenetic position within the subfamily Draconinae, Oriocalotes now becomes the second monotypic genus (after Brachysaura: see Deepak et al. 2015) in recent years to be subsumed into Calotes. The poor support in the nuclear dataset is probably due to incongruence in the individual nuclear genes (Appendix 4-6). So, additional nuclear markers need to be analysed to further resolve its position within the Calotes radiation. Our nuclear and mitochondrial trees support a clade encompassing Calotes + "Oriocalotes" + Psammophilus. Members of this radiation are largely confined to India and harbor multiple ecomorphs; Psammophilus is a predominantly rock dwelling genus with a dorsoventrally compressed body. Calotes minor is completely terrestrial with a relatively short fifth toe (Deepak et al. 2015), whereas all other Calotes (including Calotes paulus comb. nov. and Calotes zolaiking sp. nov.) are predominantly or exclusively arboreal and have a longer fifth toe.

Mahony (2010) noted that Oriocalotes shares common external morphological characters with Calotes (elongated spines on the post ocular, temporal and supratympanic regions) and Pseudocalotes (enlarged subocular scale row and heterogeneous dorsal scalation). Mahony (2010) also noted that no Calotes species possessed a noticeably enlarged subocular scale row, however, this character was found to be present or absent in the genus Diploderma Hallowell, 1861, so the plasticity of this character within Calotes (now including Oriocalotes) might not be unusual. The evolutionary relevance of this character is yet to be studied. Hallerman and Böhme (2000) (modified by Deepak et al. 2015) attribute the following characters to the genus Calotes: a broad head (HW/HL ratio 0.58-0.82), groups of spines from eye to tympanum, cheek often swollen in males, relatively long hindlimbs (hindlimb length/SVL ratio 0.62-1.01) and tail (TL/SVL ratio 0.9-3.0). Presence of regular, uniform dorsal scales, thought to be an important character in the diagnosis of the genus Calotes (Smith 1935; Manthey \& Denzer 2000), is now demonstrated to have no systematic importance, as observed in the draconine lizards belonging to the genus Bronchocela Kaup, 1827 and Pseudocalotes.

TABLE 4. Hemipenal morphological characters used for comparison with Calotes zolaiking sp. nov. Character score "1" for presence and " 0 " for absence. Numbers on top represent different species of Calotes: 1. C. calotes; 2. C. nigrilabris; 3. C. versicolor; 4. C. ceylonensis; 5. C. liolepis; 6. C. liocephalus Günther, 1872; 7. C. desilvai Bahir \& Maduwage, 2005; 8. C. minor; 9. Calotes zolaiking sp. nov. Sources: Maduwage et al. (2008); Deepak et al. (2015).

\begin{tabular}{llllllllll}
\hline Character & 1 & 2 & 3 & 4 & 5 & 6 & 7 & 8 & 9 \\
\hline Hemipenis divided for more than half its length & 0 & 0 & 0 & 0 & 0 & 0 & 0 & 0 & 0 \\
Flounces present & 0 & 0 & 0 & 0 & 0 & 0 & 0 & 0 & 0 \\
Apex of each lobe divided symmetrically both laterally and medially & 0 & 0 & 0 & 0 & 0 & 0 & 0 & 0 & 0 \\
by sulcus & & & & & & & & & \\
Sulcus spermaticus bifurcated & 1 & 1 & 1 & 1 & 1 & 1 & 1 & 1 & 1 \\
Fleshy cardioid structure at base of ventral sulcus & 1 & 1 & 1 & 1 & 1 & 1 & 1 & 1 & 0 \\
Lateral and medial sulcus distinct throughout length of each lobe & 1 & 1 & 1 & 1 & 1 & 1 & 1 & 1 & 1 \\
Length of entire organ greater than its width & 0 & 0 & 0 & 0 & 0 & 0 & 0 & 0 & 0 \\
Minute denticulation on calyces & 0 & 0 & 0 & 0 & 0 & 0 & 0 & 0 & 0 \\
Sulcus traverses apex & 0 & 0 & 0 & 0 & 0 & 0 & 0 & 0 & 0 \\
Each lobe with more than 11 flounces & 0 & 0 & 0 & 0 & 0 & 0 & 0 & 0 & 0 \\
Ventral sulcus with transverse ridges & 0 & 0 & 0 & 0 & 0 & 0 & 0 & 0 & 0 \\
Transverse ridges along more than half length of ventral sulcus & 0 & 0 & 0 & 0 & 0 & 0 & 0 & 0 & 0 \\
Calyces subequal along entire length of organ & 0 & 0 & 0 & 0 & 0 & 0 & 0 & 0 & 0 \\
Entire length of lateral and medial sulcus with calyces & 0 & 0 & 0 & 1 & 0 & 0 & 0 & 0 & 0 \\
\hline
\end{tabular}




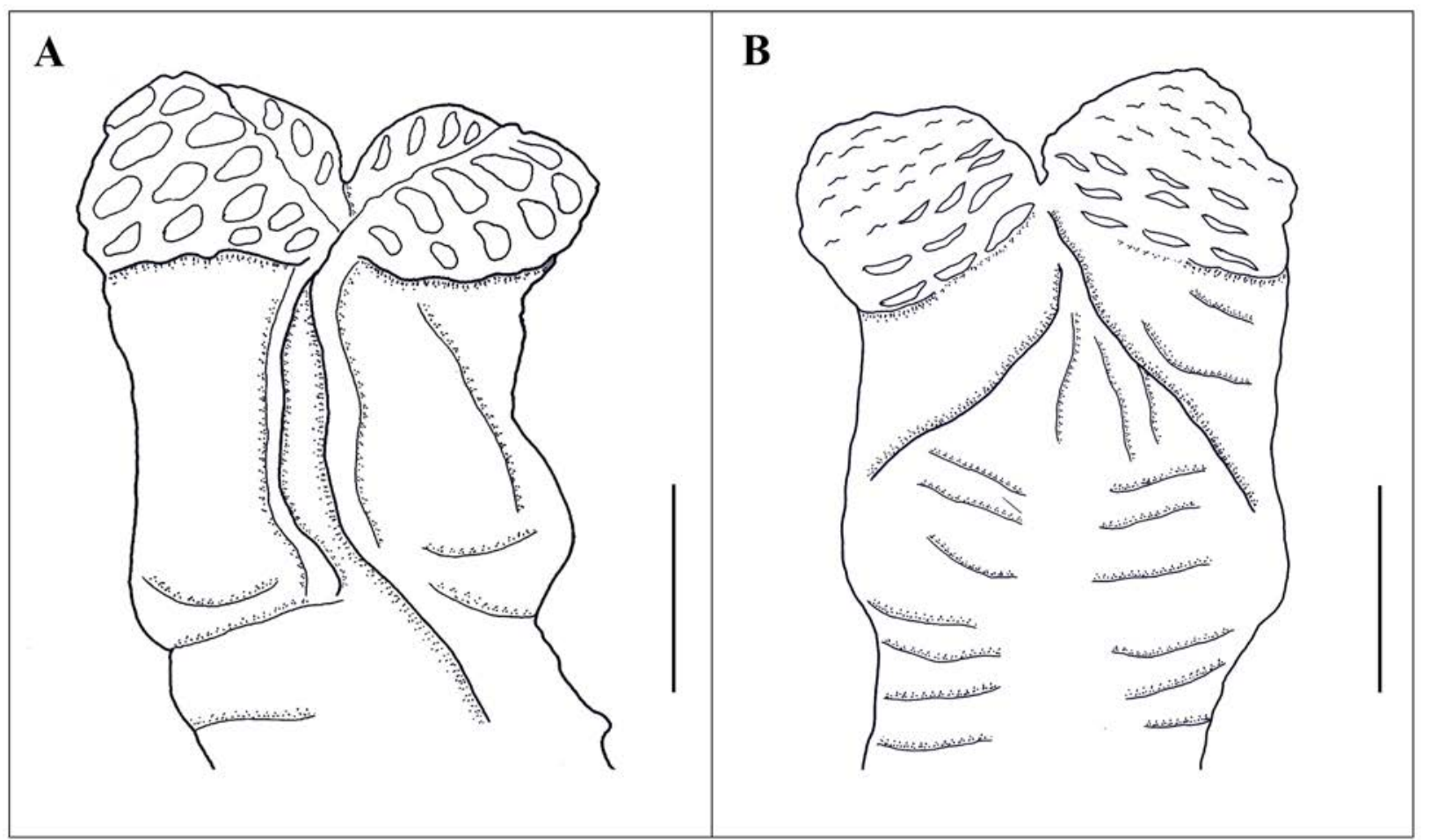

FIGURE 11. Hemipenis of referred specimen of Calotes zolaiking sp. nov. (NCBS-AU156). A. Sulcal view, B. asulcal view. Scale bar: $1 \mathrm{~mm}$.
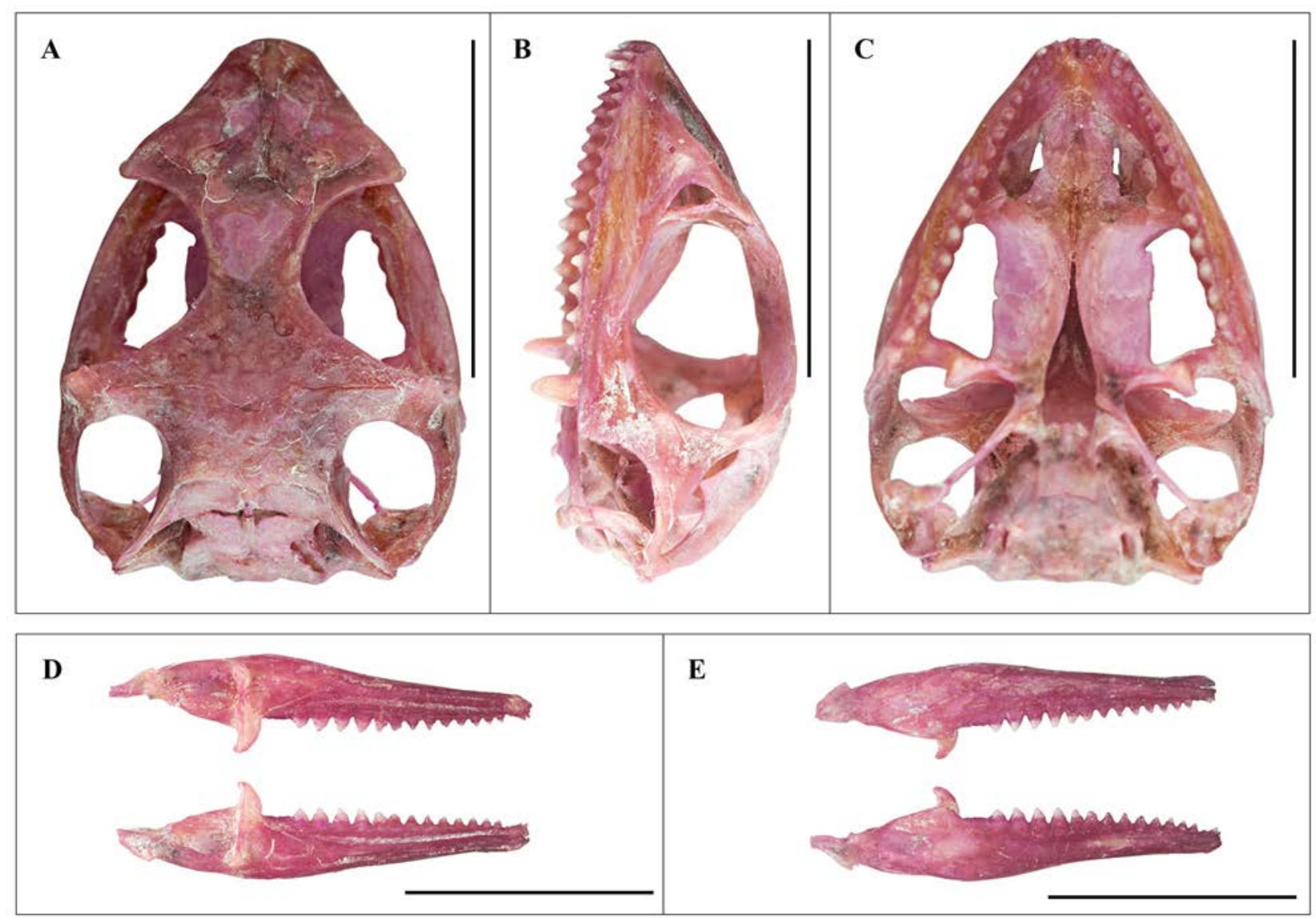

FIGURE 12. Skull of referred specimen of Calotes zolaiking sp. nov. (NCBS-AU156). A. Dorsal view, B. lateral view, C. ventral view of cranium, D. inner view of mandible, E. outer view of mandible. Scale bar: $10 \mathrm{~mm}$. 


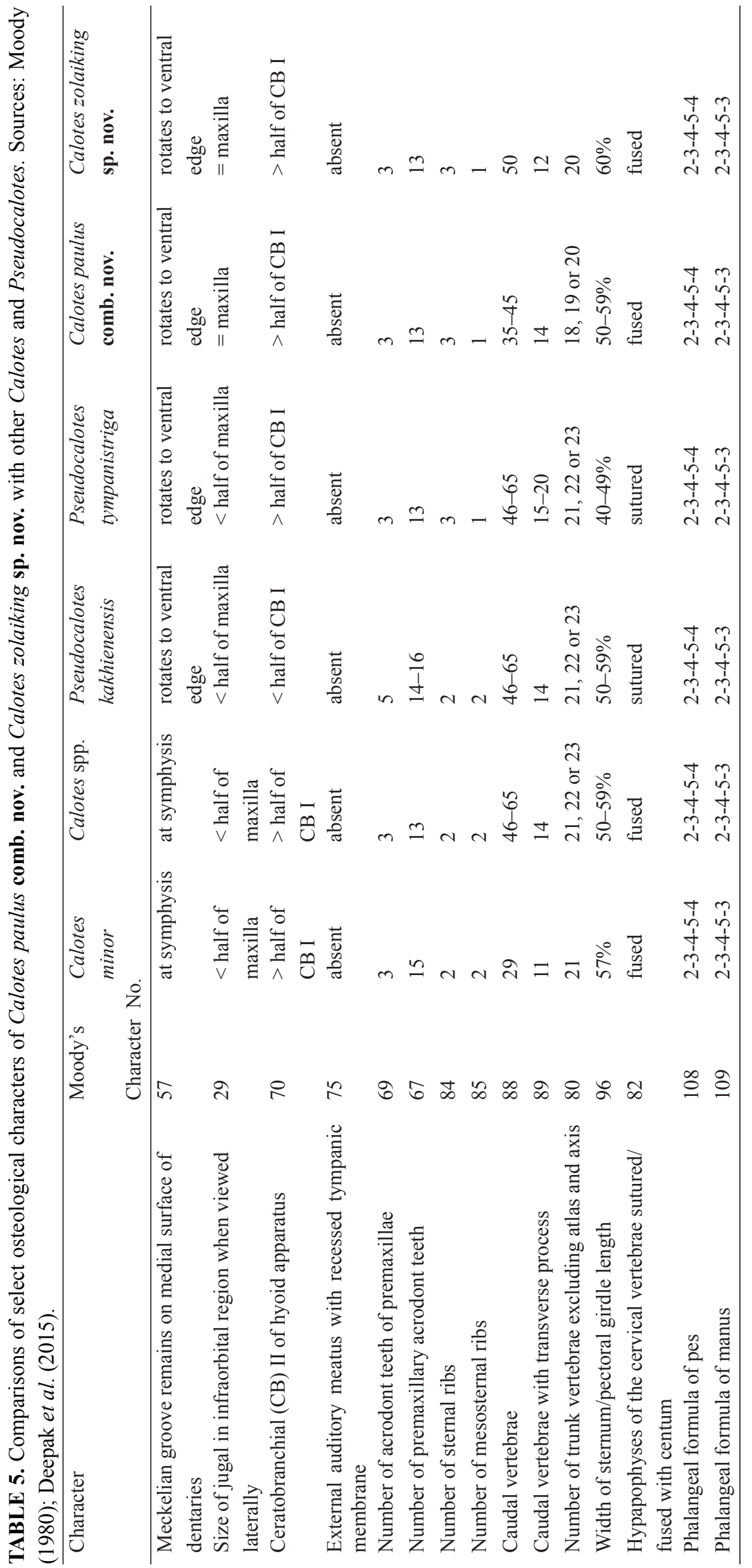


Our study reinforces the importance of hemipenial morphology as a generic diagnostic character for agamid lizards. The shape of the hemipenis is largely conserved within draconine genera (Maduwage et al. 2008; Maduwage \& Silva 2012), however, the absence of the cardioid structure on the hemipenes of Calotes zolaiking sp. nov. warrants a relook at the usage of this character to diagnose the genus Calotes (Maduwage et al. 2008; Maduwage \& Silva 2012; Deepak et al. 2015).

The osteological characters suggested by Moody (1980) to diagnose agamid genera will require revision considering the recent changes in agamid taxonomy, e.g. within the distantly related genus, Pseudocalotes, there are multiple osteological characters which are not congruent with Moody's (1980) diagnoses (Table 5). However, osteological comparisons of additional species in the genus Calotes is required to better understand homologous osteological characters. The genus-level assignment of draconine species has been historically based on synapomorphic characters. Taxonomic stability for most draconine species will only occur following detailed molecular phylogenetic analysis and a thorough reassessment of morphological characters.

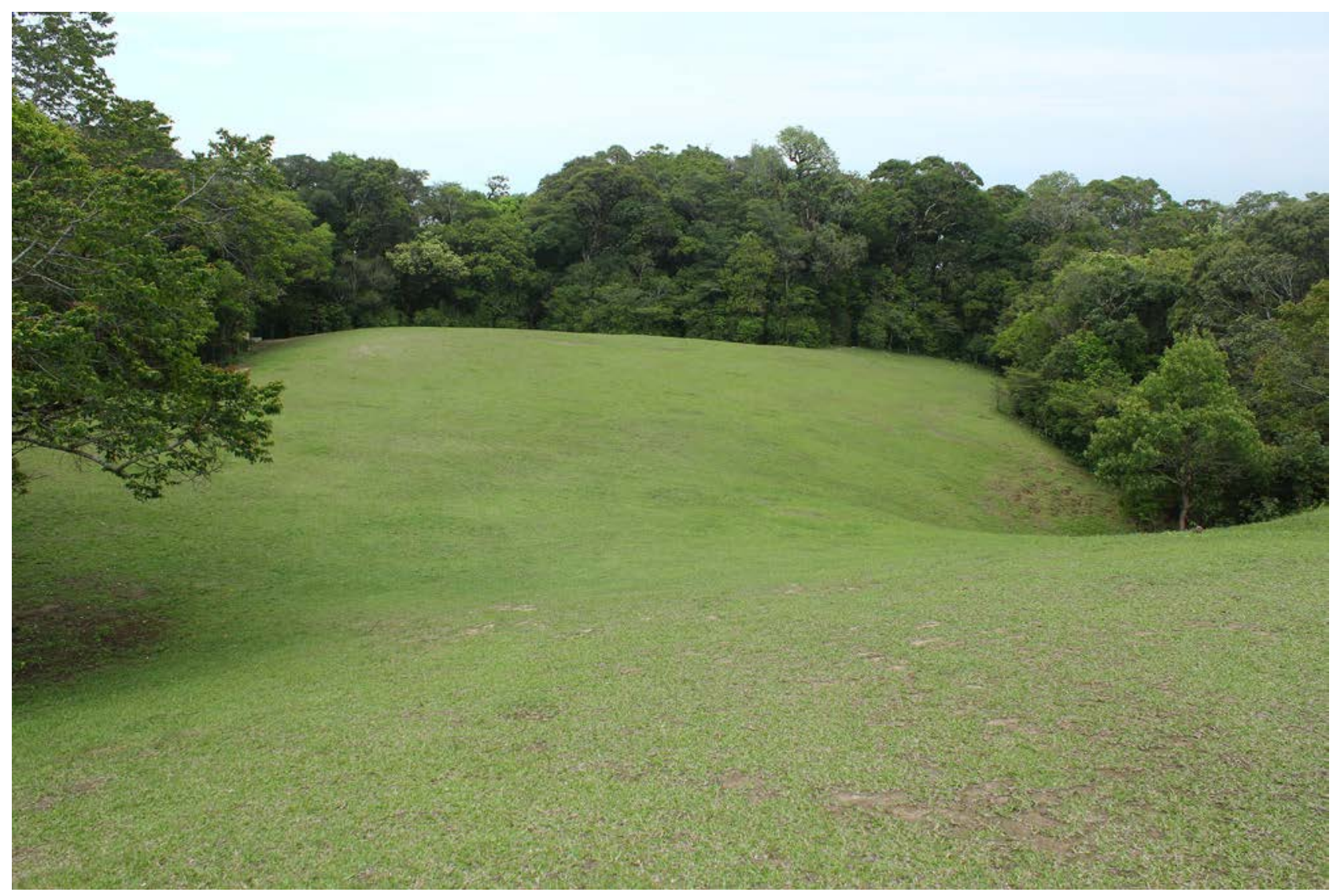

FIGURE 13. Habitat where Calotes zolaiking sp. nov. were found in Durtlang, Mizoram state, Northeast India.

\section{Conclusions}

The draconine agamid taxonomy is currently in a state of flux, however, as more molecular sequence data becomes available, our understanding of the systematic relationships within the subfamily is rapidly improving (Denzer et al. 2015; Deepak et al. 2015; Deepak et al. 2016; Deepak \& Karanth, 2018; Grismer et al. 2016; Wang et al. 2018; Pal et al. 2018). The recent generic reallocations (Pal et al. 2018, this study), along with the newly described species, $C$. manamendrai Amarasinghe and Karunarathna, 2014, C. pethiyagodai Amarasinghe, Karunarathna and Hallermann, 2014 and C. bachae Hartmann, Geissler, Poyarkov, Ihlow, Galoyan, Rödder and Böhme, 2013, increase the global Calotes diversity to 25 species. After Cristidorsa otai (Mahony, 2009) (also endemic to Mizoram state), Calotes zolaiking sp. nov. becomes the second new agamid species to have been described from Northeast India since the description of Pseudocalotes austeniana (Annandale, 1908). Further herpetological exploration of Northeast India is required to better understand the true potential of this biodiversity rich, but poorly studied region. 


\section{Acknowledgments}

VD would like to thank the Department of Biotechnology DBT-RA fellowship, and MoEFCC research funding. VD thanks SCCS Miriam Rothschild Travel Bursary Programme for their support during his visit to NHM \& David Gower and Patrick Campbell for their support at NHM, London. VD's contribution was supported, in part, by Marie Skłodowska-Curie Fellowship EU project 751567. SM is currently funded by an IRC-Marie Skłodowska-Curie CAROLINE Fellowship (CLNE/2017/482). CL would like to thank Mizoram University MZU-UGC fellowship and also Mr. V.L. Hriatzuala Sailo and Mr. Vanlalhrima for their assistance during fieldwork. SM thanks Patrick Campbell and Colin McCarthy (NHMUK) for providing access to specimens. We thank Rahul Khot (BNHS) for access to the collections, and Tarun Karmakar for providing photographs of Calotes paulus comb. nov. in life. Collection of specimens from Mizoram was done under permit No.A.33011/4/2011-CWLW/397 issued by the Chief Wildlife Warden, Environment, Forest and Climate Change, Government of Mizoram. We would like to thank Philipp Wagner and Aaron Bauer for their comments which improved this manuscript.

\section{References}

Amarasinghe, A.A.T., Karunarathna, D.M.S.S. \& Fujinuma, J. (2014) A new Calotes species from Sri Lanka with a redescription of Calotes liolepis Boulenger, 1885. Herpetologica, 70, 323-338.

https://doi.org/10.1655/HERPETOLOGICA-D-13-00087

Amarasinghe, A.T., Karunarathna, D.M.S.S., Hallermann, J., Fujinuma, J., Grillitsch, H. \& Campbell, P.D. (2014) A new species of the genus Calotes (Squamata: Agamidae) from high elevations of the Knuckles Massif of Sri Lanka. Zootaxa, 3785 (1), 59-78. http://doi.org/10.11646/zootaxa.3785.1.5

Ananjeva, N.B., Guo, X. \& Wang, Y. (2011) Taxonomic diversity of agamid lizards (Reptilia, Sauria, Acrodonta, Agamidae) from China: A comparative analysis. Asiatic Herpetological Research, 2, 117-128. https://doi.org/10.3724/SP.J.1245.2011.00117

Anderson, J. (1879) Reptilia and Amphibia. In: Anatomical and Zoological Researches: Comprising an Account of the Zoological Results of the Two Expeditions to Western Yunnan in 1868 and 1875. Bernard Quarich, London, "1878". [Two volumes text: 985 pp. (herpetology: pp. 703-860+969-975); Atlas: 85 pls. (herpetological pls. 55-78+75A + 75B)] https://doi.org/10.5962/bhl.title.50434

Annandale, N. (1908) Description of a new species of lizard of the genus Salea from Assam. Records of the Indian Museum, 2 , $37-38$.

Bahir, M.M. \& Maduwage, K.P. (2005) Calotes desilvai, a new species of agamid lizard from Morningside Forest, Sri Lanka. Raffles Bulletin of Zoology, 12, 381-392.

Beddome, R.H. (1878) Description of a new genus of tree-lizard from the higher ranges of the Anamallays. Proceedings of the Zoological Society of London, 1877, 153. https://doi.org/10.1111/j.1469-7998.1878.tb07945.x

Benson, D.A., Cavanaugh, M., Clark, K., Karsch-Mizrachi, I., Lipman, D.J., Ostell, J. \& Sayers, E.W. (2017) GenBank. Nucleic Acids Research, 45 (Database Issue), D37-D42. https://doi.org/10.1093/nar/gkw1070

Biju, S.D., Senevirathne, G., Garg, S., Mahony, S., Kamei, R.G., Thomas, A., Shouche, Y., Raxworthy, C.J., Meegaskumbura, M. \& Van Bocxlaer, I. (2016) Frankixalus, a new rhacophorid genus of tree hole breeding frogs with oophagous tadpoles. PLoS ONE, 11, e 0145727 . http://doi.org/10.1371/journal.pone.0145727

Blanford, W.T. (1870) Notes on some Reptilia and Amphibia from Central India. Journal of the Asiatic Society of Bengal, 39 , 335-376, pls. XIV-XVI.

Boulenger, G.A. (1885) Catalogue of the Lizards in the British Museum (Nat. Hist.) I. Geckonidae, Eublepharidae, Uroplatidae, Pygopodidae, Agamidae. Trustees of British Museum, London, xii + 436 pp., XXXII pls.

Champion, H.G. \& Seth, S.K. (1968) A revised survey of the forest types of India. Government of India Press, Nasik, 404 pp.

Daudin, F. (1802) Histoire Naturelle, Générale et Particulière des Reptiles. "1803”. Vol. III. F. Dufart, Paris, 452 pp.

Deepak, V., Vyas, R., Giri, V.B. \& Karanth, K.P. (2015) A taxonomic mystery for more than 180 years: the identity and systematic position of Brachysaura minor (Hardwicke \& Gray, 1827) Vertebrate Zoology, 65, 371-381.

Deepak, V., Giri, V.B., Asif, M., Dutta, S.K., Vyas, R., Zambre, A.M., Bhosale, H. \& Karanth, K.P. (2016) Systematics and phylogeny of Sitana (Reptilia: Agamidae) of Peninsular India, with description of one new genus and five new species. Contributions to Zoology, 85, 67-111.

Deepak, V. \& Karanth, P. (2018) Aridification driven diversification of fan-throated lizards from the Indian subcontinent. Molecular Phylogenetics and Evolution, 120, 53-62. https://doi.org/10.1016/j.ympev.2017.11.016 
Denzer, W., Manthey, U., Mahlow, K. \& Böhme W. (2015) The systematic status of Gonocephalus robinsonii Boulenger, 1908 (Squamata: Agamidae: Draconinae). Zootaxa, 4039 (1), 129-144.

https://doi.org/10.11646/zootaxa.4039.1.5

Diong, C.H. \& Lim, S.S.L. (1998) Taxonomic review and morphometric description of Bronchocela cristatella (Kuhl, 1820) (Squamata: Agamidae) with notes on other species in the genus. The Raffles Bulletin of Zoology, 46, 345-359.

Duméril, A.M.C. \& Bibron, G. (1837) Erpétologie Générale ou Histoire Naturelle Complete des Reptiles. Tome Quatrième. Contenant l'Histoire de Quarante-Six Genres et de Cent Quarante-Six Espèces de la Famille des Iguaniens, de l'Ordre des Sauriens. Librairie Encyclopédique de Roret, Paris, ii + 571 pp., pls. XXIX-XXXII, XXXIV, XXXVI, XXXVIII, XL-XLII, L, LV

Gray, J.E. (1831) A synopsis of the species of the Class Reptilia. In: Griffith, E. \& Pidgeon, E. (Ed.), The Animal Kingdom arranged in conformity with its organization, by the Baron Cuvier, with additional descriptions of all the species hitherto named, and of many not before noticed. Vol. 9. The class Reptilia arranged by the Baron Cuvier, with specific descriptions. Whittaker, Treacher, and Co., London, pp. 483-600.

Gray, J.E. (1845) Catalogue of the Specimens of Lizards in the Collection of the British Museum. Trustees of the British Museum, London, xxvii + 289 pp.

Grismer, J.L., Schulte, J.A., Alexander, A., Wagner, P., Travers, S.L., Buehler, M.D., Welton, L.J. \& Brown, R.M. (2016) The Eurasian invasion: phylogenomic data reveal multiple Southeast Asian origins for Indian Dragon Lizards. BMC Evolutionary Biology, 16, 1-11. https://doi.org/10.1186/s12862-016-0611-6

Groth, J.G. \& Barrowclough, G.F. (1999) Basal divergences in birds and the phylogenetic utility of the nuclear RAG-1 Gene. Molecular Phylogenetics and Evolution, 12, 115-123. https://doi.org/10.1006/mpev.1998.0603

Günther, A. (1864) The Reptiles of British India. Taylor \& Francis, London. xxvii + 452 pp., XXVI pls.

Hallermann, J. \& Böhme, W. (2000) A review of the genus Pseudocalotes (Squamata: Agamidae), with description of a new species from West Malaysia. Amphibia-Reptilia, 21, 193-210. https://doi.org/10.1163/156853800507372

Hallowell, E. (1861) Report upon the Reptilia of the North Pacific Exploring Expedition, under command of Capt. John Rogers, U. S. N. Proceedings of the Academy of Natural Sciences of Philadelphia, 12, 480-510.

Hanken, J. \& Wassersug, R. (1981) The visible skeleton: a new double-stain technique reveals the nature of the "hard" tissues. Functional Photography, 16, 22-44.

Hardwicke, T. \& Gray, J.E. (1827) A synopsis of the species of saurian reptiles, collected in India by Major-General Hardwicke. Zoological Journal, 3, 213-229.

Hartmann, T., Geissler, P., Nikolay, A.J., Ihlow, P.F., Galoyan, E.A., Rödder, D \& Böhme, W. (2013) A new species of the genus Calotes Cuvier, 1817 (Squamata: Agamidae) from southern Vietnam. Zootaxa, 3599 (3), 246-260. https://doi.org/10.11646/zootaxa.3599.3.3

Higgins, D., Thompson, J., Gibson, T. Thompson, J.D., Higgins, D.G. \& Gibson, T.J. (1994). CLUSTAL W: improving the sensitivity of progressive multiple sequence alignment through sequence weighting, position-specific gap penalties and weight matrix choice. Nucleic Acids Research, 22, 4673-4680. https://doi.org/10.1093/nar/22.22.4673

Huang, Y., Dai, Q., Chen, Y., Wan, H., Li, J. \& Wang, Y. (2011) Lizard species richness patterns in China and its environmental associations. Biodiversity and Conservation, 20 (7), 1399-1414. https://doi.org/10.1007/s10531-011-0033-0

International Commission of Zoological Nomenclature [ICZN] (1999) International code of zoological nomenclature [the Code]. $4^{\text {th }}$ Edition. The International Trust for Zoological Nomenclature, c/o Natural History Museum, London, xxix, + 306 pp. [online version at http://www.iczn.org/iczn/index.jsp]

Jerdon, T.C. (1870) Notes on Indian herpetology. Proceedings of the Asiatic Society of Bengal, 1870, 66-85

Lanfear, R., Calcott, B., Ho, S.Y.W. \& Guindon, S. (2012) Partitionfinder: combined selection of partitioning schemes and substitution models for phylogenetic analyses. Molecular Biology and Evolution, 29, 1695-1701.

https://doi.org/10.1093/molbev/mss020

Leaché, A.D. (2009) Species tree discordance traces to phylogeographic clade boundaries in 132 North American fence lizards (Sceloporus). Systematic Biology, 58, 547-559. https://doi.org/10.1093/sysbio/syp057

Li, P., Zhao, E. \& Dong, B. (2010) Amphibians and Reptiles of Tibet. Science Press, Beijing, XII + 251 pp.

Macey, R.J, Larson, A., Ananjeva, N.B., Fang, Z. \& Papenfuss, T. (1997) Two novel gene orders and the role of light-strand replication in rearrangement of the vertebrate mitochondrial genome. Molecular Biology and Evolution, 14, 91-104. https://doi.org/10.1093/oxfordjournals.molbev.a025706

Macey, R.J., Schulte II, J.A., Larson, A., Ananjeva, N.B., Wang, Y., Pethiyagoda, R., Rastegar-Pouyani, N. \& Papenfuss, T.J. (2000) Evaluating Trans-Tethys migration: An example using acrodont lizard phylogentics. Systematic Biology, 49, 233256. https://doi.org/10.1093/sysbio/49.2.233

Maduwage, K., Meegaskumbura, M., Silva, A. \& Pethiyagoda, R. (2008) Phylogenetic implications of hemipenial morphology 
in Sri Lankan agamid lizards. Current Science, 95, 838-840.

Maduwage, K. \& Silva, A. (2012) Hemipeneal morphology of Sri Lankan dragon lizards (Sauria: Agamidae). Ceylon Journal of Science, Biological Sciences, 41, 111-123.

https://doi.org/10.4038/cjsbs.v41i2.5381

Mahony, S. (2009) A new species of Japalura (Reptilia: Agamidae) from northeast India with a discussion of the similar species Japalura sagittifera Smith, 1940 and Japalura planidorsata Jerdon, 1870. Zootaxa, 2212, 41-61.

Mahony, S. (2010) Systematic and taxonomic revaluation of four little known Asian agamid species, Calotes kingdonwardi Smith, 1935, Japalura kaulbacki Smith, 1937, Salea kakhienensis Anderson, 1879 and the monotypic genus Mictopholis Smith, 1935 (Reptilia: Agamidae). Zootaxa, 2514 (1), 1-23. https://doi.org/10.11646/zootaxa.2514.1.1

Mahony, S., Kamei, R.G., Teeling, E.C. \& Biju, S.D. (2018) Cryptic diversity within the Megophrys major species group (Amphibia: Megophryidae) of the Asian horned frogs: Phylogenetic perspectives and a taxonomic revision of South Asian taxa, with descriptions of four new species. Zootaxa, 4523 (1), 1-96. https://doi.org/10.11646/zootaxa.4523.1.1

Manthey, U. \& Nabhitabhata, J. (1991) Eine neue Agame, Ptyctolaemus phuwuanensis sp. n. (Sauria: Agamidae), aus NordostThailand. Sauria, 13, 3-6.

Manthey, U. \& Schuster, N. (1999) Agamen, 2. Natur und Tier Verlag, Münster, 120 pp.

Manthey, U. \& Denzer, W. (2000) Description of a new genus, Hypsicalotes gen.nov. (Sauria: Agamidae) from Mount Kinabalu, North Borneo, with remarks on the generic identity of Gonocephalus schultzewestrumi Urban, 1999. Hamadryad, 25, 13-20.

Moody, S.M. (1980) Phylogenetic and historical biogeographical relationship of the genera in the family Agamidae (Reptilia: Lacertilia). PhD thesis, The University of Michigan, Ann Arbor, 373 pp.

Müller, F. (1887) Fünfter Nachtrag zum Katalog der herpetologischen Sammlung des Basler Museums. Verhandlungen der Naturforschenden Gesellschaft in Basel, 8, 249-296. https://doi.org/10.5962/bhl.part.19447

Oelrich, T.M. (1956) The anatomy of the head of Ctenosaura pectinate (Iguanidae). University of Michigan Museum of Zoology Miscellaneous Publications, 94, 1-122. https://doi.org/10.2307/1440299

Pal, S., Vijayakumar, S.P., Shanker, K., Jayarajan, A. \& Deepak, V. (2018) A systematic revision of Calotes Cuvier, 1817 (Squamata: Agamidae) from the Western Ghats adds two genera and reveals two new species. Zootaxa, 4482 (3), 401-450. https://doi.org/10.11646/zootaxa.4482.3.1

Palumbi, S.R., Martin, A., Romano, S., McMillan, W.O., Stice, L. \& Grabowski, G. (1991) The Simple Fool's Guide to PCR. Department of Zoology and Kewalo Marine Laboratory, University of Hawaii, Honolulu.

Pyron, R.A., Burbrink, F.T. \& Wiens, J.J. (2013) A phylogeny and revised classification of Squamata, including 4161 species of lizards and snakes. BMC Evolutionary Biology, 13, 93. https://doi.org/10.1186/1471-2148-13-93

Romer, A.S. (1956) Osteology of the Reptiles. University of Chicago Press, Chicago, 772 pp.

Ronquist, F., Teslenko, M., Van Der Mark, P., Ayres, D., Darling, A., Höhna, S., Larget, B., Liu, L., Suchard, M.A. \& Huelsenbeck, J.P. (2012) MrBayes 3.2: efficient Bayesian phylogenetic inference and model choice across a large model space. Systematic Biology, 61, 539-542. https://doi.org/10.1093/sysbio/sys029

Schulte II, J.A., Vindum, J.V., Win, H., Thin, T., Lwin, K.S., Shein, A.K. \& Tun, H. (2004) Phylogenetic relationships of the genus Ptyctolaemus (Squamata: Agamidae), with a description of a new species from the Chin Hills of western Myanmar. Proceedings of the California Academy of Sciences, 55, 222-247.

Silvestro, D. \& Michalak, I. (2012) raxmlGUI: a graphical front-end for RAxML. Organism Diversity and Evolution, 12 , 335-337. https://doi.org/10.1007/s13127-011-0056-0

Smith, M.A. (1935) The Fauna of British India, including Ceylon and Burma. Reptiles and Amphibia. Vol. II. Sauria. Taylor and Francis, London, xiii +440 pp., pls. $1+2$ maps.

Stamatakis, A., Ludwig, T. \& Meier, H. (2005) RAxML-III: a fast program for maximum likelihood-based inference of large phylogenetic trees. Bioinformatics, 21, 456-463. https://doi.org/10.1093/bioinformatics/bti191

Stamatakis, A. (2006) RAxML-VI-HPC: maximum likelihood-based phylogenetic analyses with thousands of taxa and mixed models. Bioinformatics, 22, 2688-2690. https://doi.org/10.1093/bioinformatics/bt1446

Tamura, K., Peterson, D., Peterson, N., Stecher, G., Nei, M. \& Kumar, S. (2011) MEGA 5: Molecular Evolutionary Genetics Analysis version 5.1. Molecular Biology and Evolution, 30, 2725-2729. https://doi.org/10.1093/molbev/mst197

Theobald, W. (1876) Descriptive Catalogue of the Reptiles of British India. Thacker, Spink and Co., Calcutta, xxxviii +238 pp. https://doi.org/10.5962/bhl.title.5483 
Venugopal, P. (2010) An updated and annotated list of Indian lizards (Reptilia: Sauria) based on a review of distribution records and checklists of Indian reptiles. Journal of Threatened Taxa, 2 (3), 725-738. https://doi.org/10.11609/JoTT.o2083.725-38

Vindum, J.V., Win, H., Thin, T., Lwin, K.S., Shein, A.K. \& Tun, H. (2003) A new Calotes (Squamata: Agamidae) from the IndoBurman range of western Myanmar (Burma). Proceedings of the California Academy of Sciences, 54, 1-16.

Wang, K., Che, J., Lin, S., Deepak, V., Datta-Roy, A., Jiang, K., Jin, J., Chen, H. \& Siler, C.D. (2018) Multilocus phylogeny and revised classification for mountain dragons of the genus Japalura sl. (Reptilia: Agamidae: Draconinae) from Asia. Zoological Journal of the Linnean Society, 185, 246-267. https://doi.org/10.1093/zoolinnean/zly034

Wermuth, H. (1967) Liste der rezenten Amphibien und Reptilien: Agamidae. Das Tierreich 86. Walter der Gruyter \& Co., Berlin, $\mathrm{XIV}+127 \mathrm{pp}$.

Zhao, E.-M. \& Adler, K. (1993) Herpetology of China. SSAR, Oxford, Ohio, $552+$ [v] pp., $48+1$ pls.

Zhao, E., Chang, H.-W., Zhao, H. \& Adler, K. (2000) Revised checklist of Chinese Amphibia and Reptilia. Sichuan Journal of Zoology, 19 (3), 196-207.

Zug, G.R., Brown, H.H., Schulte, J.A. \& Vindum, J.V. (2006) Systematics of the garden lizards, Calotes versicolor Group (Reptilia, Squamata, Agamidae), in Myanmar: Central Dry Zone populations. Proceedings of the California Academy of Sciences, 57, 35-68.

APPENDIX 1. Partitions and models of sequence evolution used in the Bayesian analyses (BI) for the mitochondrial and nuclear genes.

\begin{tabular}{|c|c|c|}
\hline Partitions & Sites & Model \\
\hline $\mathrm{P} 1$ & ND2 $1^{\text {st }}$ & $\mathrm{GTR}+\mathrm{I}+\mathrm{G}$ \\
\hline $\mathrm{P} 2$ & $\mathrm{ND} 22^{\text {nd }}$ & $\mathrm{HKY}+\mathrm{I}+\mathrm{G}$ \\
\hline P3 & $\mathrm{ND} 23^{\text {rd }}$ & $\mathrm{GTR}+\mathrm{I}+\mathrm{G}$ \\
\hline P4 & $16 \mathrm{~S}$ & $\mathrm{GTR}+\mathrm{I}+\mathrm{G}$ \\
\hline $\mathrm{P} 1$ & R35 $1^{\text {st }}$, RAG1 $1^{\text {st }}$, RAG12 $2^{\text {nd }}$ & $\mathrm{K} 80+\mathrm{G}$ \\
\hline $\mathrm{P} 2$ & PTGER $2^{\text {nd }}$, PTGER $3^{\text {rd }}, R 352^{\text {nd }}$ & K80 \\
\hline P3 & $\mathrm{R} 353^{\text {rd }}, \mathrm{RAG} 13^{\text {rd }}$ & $\mathrm{K} 80+\mathrm{G}$ \\
\hline P4 & PTGER $1^{\text {st }}$ & $\mathrm{HKY}+\mathrm{I}$ \\
\hline
\end{tabular}

APPENDIX 2. Specimens examined.

Calotes jerdonii:BMNH 1946.8.11.50-51, BMNH 1946.8.11.54-53, BMNH 1946.8.11.56

Calotes emma: BMNH 1946.8.11.26

Calotes maria: BMNH 1946.8.11.24

Calotes grandisquamis: BMNH 1946.8.11.44-47

Calotes nemoricola: BMNH 74.4.29.224-225

Calotes bhutanensis: ZSI 22480

Calotes nigrilabris: NMI 2007.106.32

Ceratophora aspera: NMI 2007.106.33

Ceratophora tennentii: NMI 2007.106.1

Cophotis ceylanica: NMI 2007.106.36

Pseudocalotes brevipes: BMNH 1946.8.11.22

Pseudocalotes dringi: BMNH 1906.2.28.10 (holotype)

Pseudocalotes flavigula: BMNH 1946.8.11.14

Pseudocalotes floweri: BMNH 1932.8.1.2

Pseudocalotes microlepis: BMNH 1946.8.11.21 (type), BMNH 1921.4.1.118

Pseudocalotes tympanistriga: BMNH 1929.11.2.1; BMNH 1848.5.20.4

Salea anamallayana: BMNH 1964.8.14.84 (type)

Salea horsfieldii: BMNH 1946.8.14.11-12 (types) 


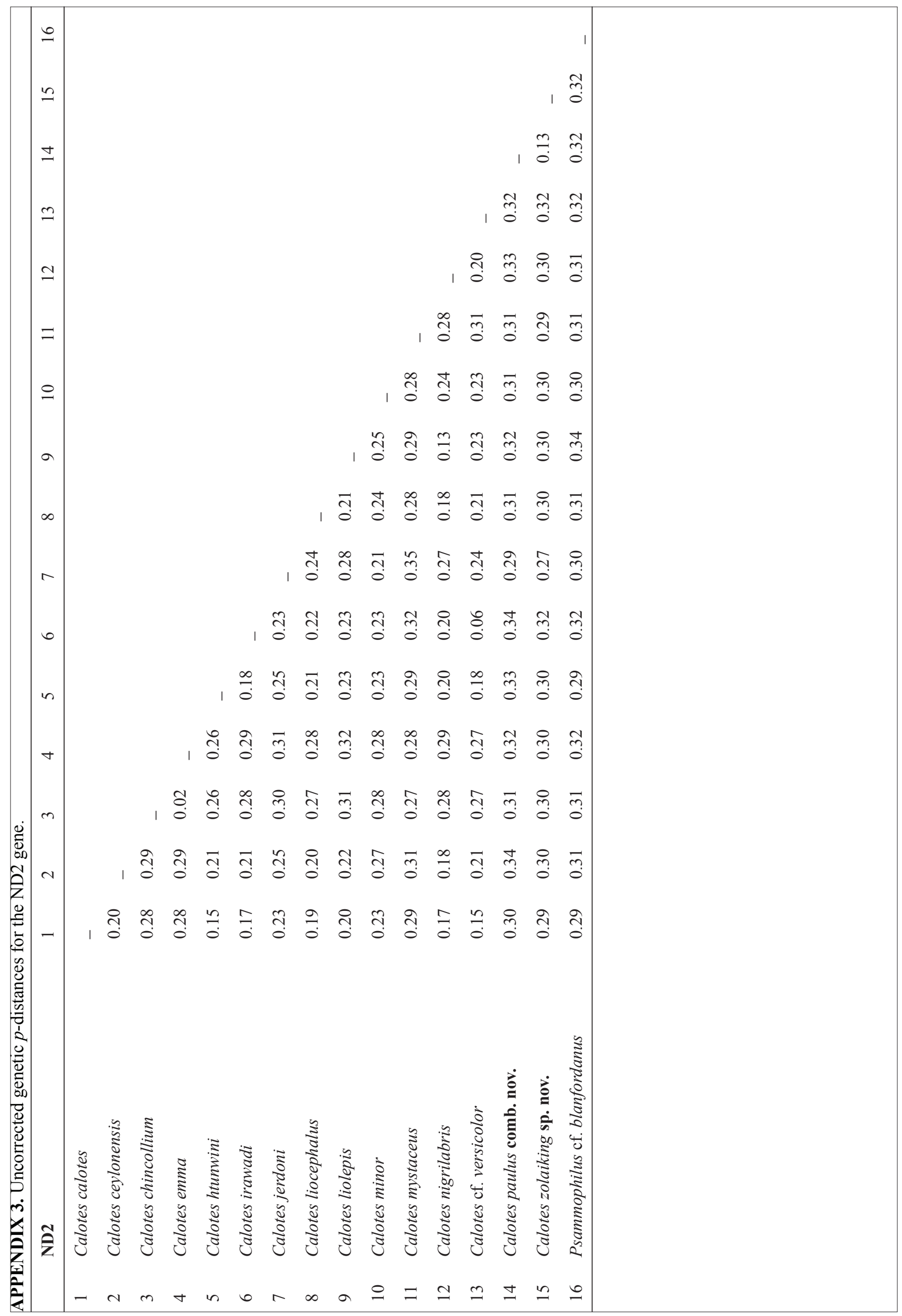




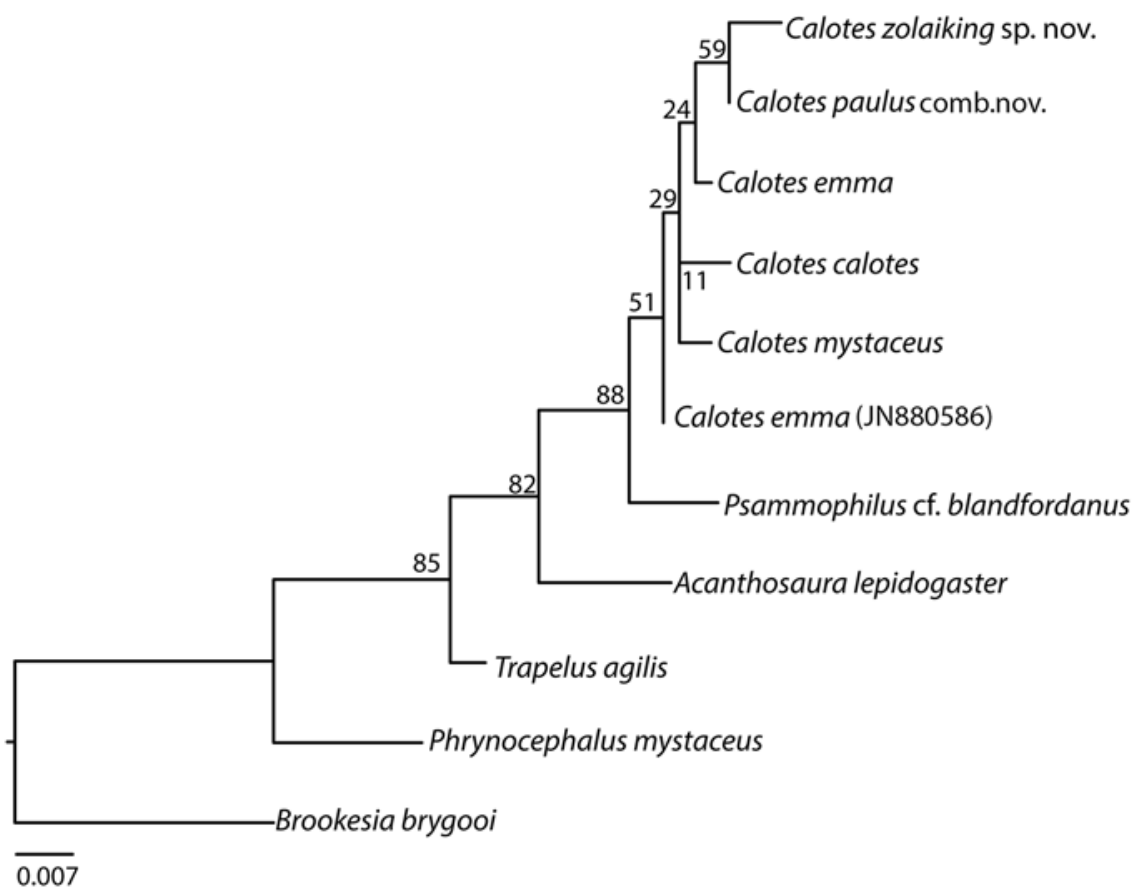

APPENDIX 4. Maximum Likelihood phylogeny constructed using PTGER dataset.

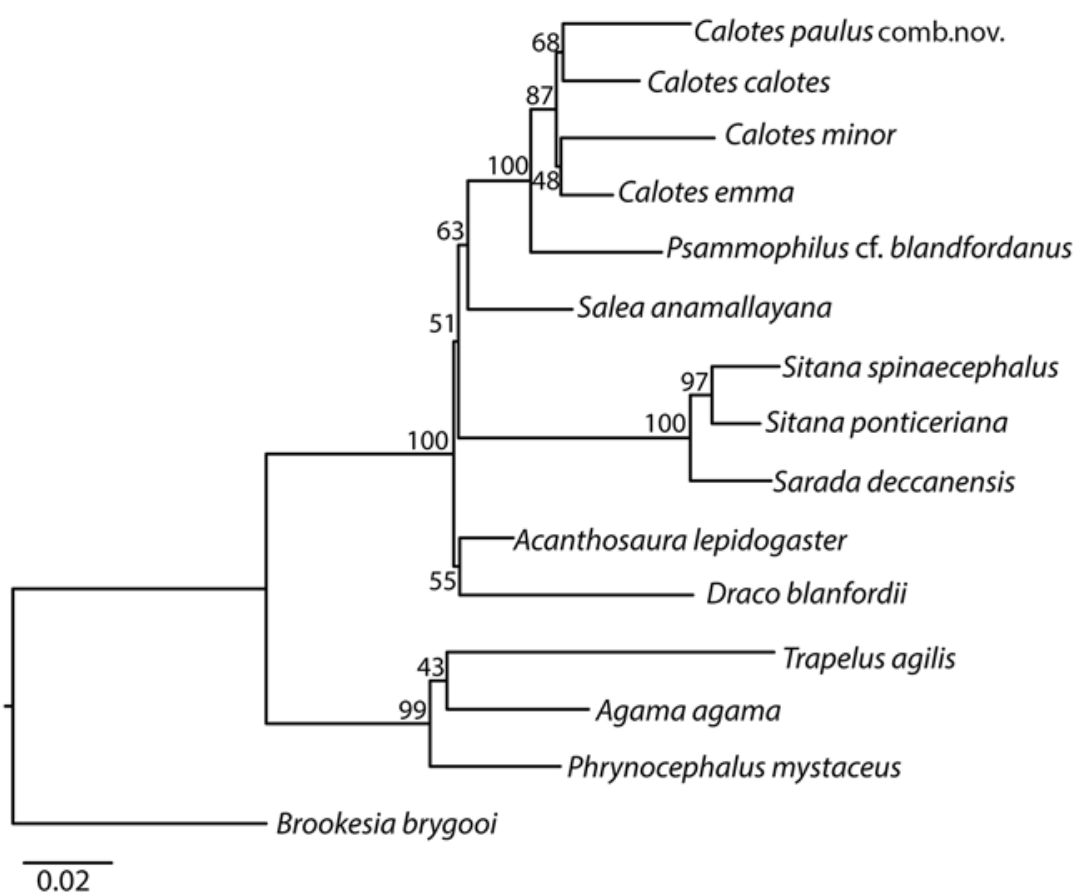

APPENDIX 5. Maximum Likelihood phylogeny constructed using RAG1 dataset. 


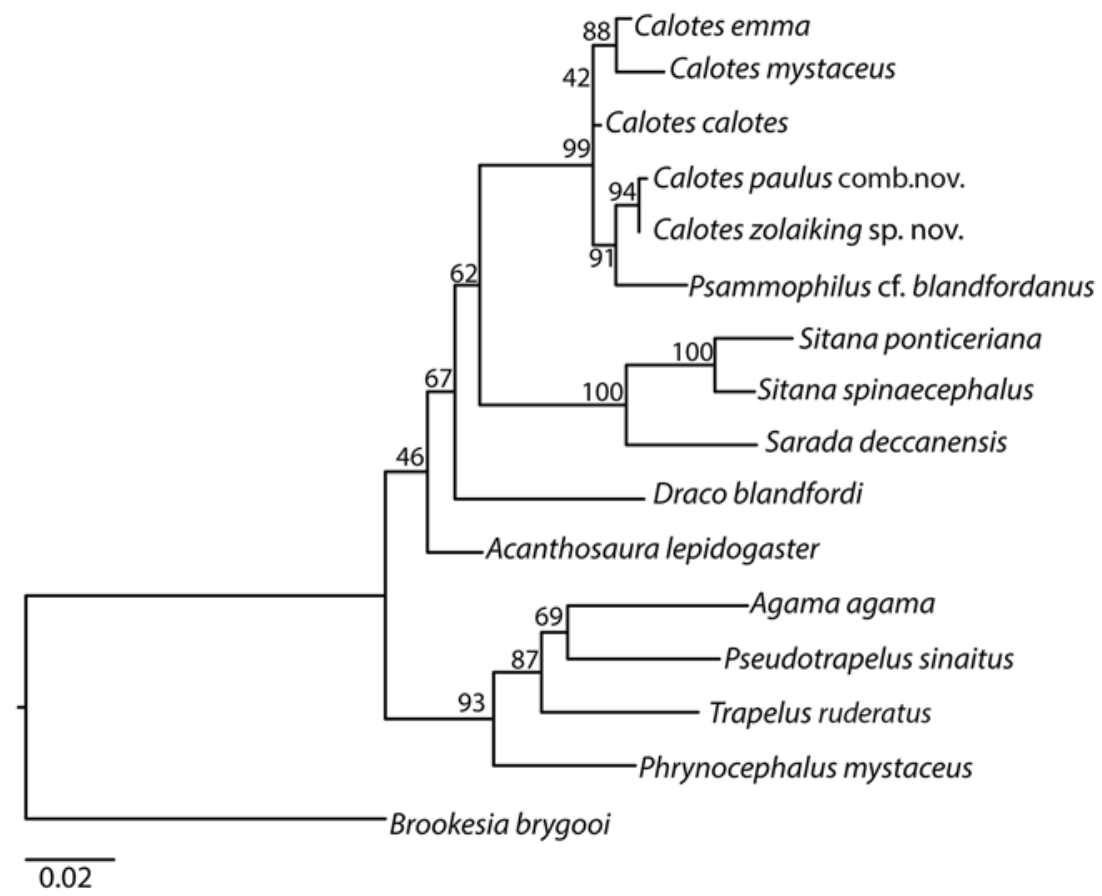

APPENDIX 6. Maximum Likelihood phylogeny constructed using R35 dataset. 